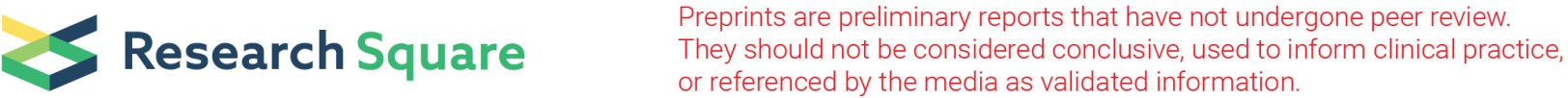

\section{TpIRT1 is a transition metal transporter in Polish Wheat (Triticum polonicum L.) with a broad substrate specificity}

\section{Yulin Jiang}

Sichuan Agricultural University

\section{Xing Chen}

Sichuan Agricultural University

Songyue Chai

Sichuan Agricultural University

Huajin Sheng

University of Saskatchewan

\section{Lina Sha}

Sichuan Agricultural University

\section{Xing Fan}

Sichuan Agricultural University

Jian Zeng

Sichuan Agricultural University

Houyang Kang

Sichuan Agricultural University

Haiqin Zhang

Sichuan Agricultural University

\section{Xue Xiao}

Sichuan Agricultural University

\section{Yonghong Zhou}

Sichuan Agricultural University

\section{Olena K. Vatamaniuk}

School of Integrative Plant Science

Yi Wang ( $\nabla$ wangyi@sicau.edu.cn )

Sichuan Agricultural University

\section{Manuscript}

Keywords: Polish wheat, IRT1, metal, transport, expression 
Posted Date: February 9th, 2021

DOI: https://doi.org/10.21203/rs.3.rs-189660/v1

License: (c) (i) This work is licensed under a Creative Commons Attribution 4.0 International License. Read Full License 


\section{Abstract}

Aims (1) Explore the metal substrate specificity of homologous TpIRT1A and TpIRT1B transporters from dwarf Polish wheat by expressing them in protoplast, yeast, and transgenic Arabidopsis; (2) screen polymorphic residues of IRT1 homologs from tetraploid and diploid ancestral wheat species that change the substrate specificity.

Methods Two IRT1 homoeologs were isolated from A (TPIRT1A) and B (TpIRT1B) genomes of a tetraploid crop, polish wheat (Triticum polonicum). Both of them were analysed by expressing them in yeast and Arabidopsis protoplast, respectively. Then we constructed over-expressing transgenic plants of TpIRT1B for metals property analysis in Arabidopsis. We also isolated 22 IRT1 homoeologs from tetraploid and diploid ancestral wheat species and expressed them in yeast for function analysis.

Results Our data highlighted the importance of TpIRT1 in the uptake and translocation of Fe, Mn, Co, and Cd with direct implications for wheat yield potential. Both TpIRT1A and TpIRT1B were located at the plasma membrane and internal vesicles in Arabidopsis protoplasts, and responsible for $\mathrm{Cd}$ and $\mathrm{Co}$ sensitivity in yeast. The over-expression of TpIRT1B in $A$. thaliana increased $\mathrm{Fe}, \mathrm{Mn}, \mathrm{Co}$, and $\mathrm{Cd}$ concentration in its tissues and improved plant growth under $\mathrm{Fe}, \mathrm{Mn}$, and Co deficiencies, while causing more sensitivity to $\mathrm{Cd}$ than wild-type plant. Functional analysis of $I R T 1$ homoeologs from tetraploid and diploid ancestral wheat species in yeast disclosed four distinct amino acid residues in TdilRT1B ( $T$. dicoccum) and TtuIRT1B (T. turgidum). Altogether, these results increase the knowledge of IRT1 function in a global crop, wheat.

\section{Introduction}

Adequate uptake of micronutrients including iron ( $\mathrm{Fe})$, zinc $(\mathrm{Zn})$, copper $(\mathrm{Cu})$ and manganese $(\mathrm{Mn})$ from the soil into plant roots, root-to-shoot delivery and lateral distribution is critical for the growth and development of plants (Kumar et al. 2009; Kobayashi and Nishizawa 2012; Yamaji et al. 2013). Thus, micronutrient deficiency in soils adversely influences crop growth and yield and results in a poor quality of plant-based food, which, in turn, negatively influences the health and well-being of the world's population (Grotz and Guerinot 2006). However, the over-accumulation of Fe, Zn, and Mn in plant cells causes toxicity with the detrimental consequences for crop growth and yield as well (Uriu-Adams and Keen 2005; Valko et al. 2005). Additionally, highly toxic and non-essential metals, such as cadmium (Cd) and lead $(\mathrm{Pb})$, compete with micronutrients for uptake and internal transport, posing a threat to plant growth and human health (Benavides et al. 2005; Wierzbicka et al. 2007; Zhai et al. 2014).

A number of mineral nutrient transport proteins facilitate a controlled absorption of minerals from the soil into root epidermal cells, internal mineral elements transport and loading to edible plant tissues, including grains (Gayomba et al. 2015). These transporters include heavy metal ATPases (HMAs) (Sasaki et al. 2014; Wang et al. 2018), natural resistance-associated macrophage proteins (NRAMPs) (Pottier et al. 2015), cation diffusion facilitators (CDFs) (Williams et al. 2000), ZRT/IRT-related protein family (ZIPs) 
(Guerinot 2000), ABC transporters (Cheng et al. 2011; Song et al. 2014), Yellow Stripe-Like (YSL) proteins (Curie et al. 2001), Cu Transporters (COPTs) (Yuan et al. 2011), and oligopeptide transporters (OPTs) (Zhai et al. 2014). Among these transporters, Iron Regulated Transporters (IRTs) that belong to the ZIP family have been functionally characterized in many plant species (Korshunova et al. 1999; Ivanov et al. 2012; Urzica et al. 2012). It is well-established now that IRT1-like proteins are the main contributors to $\mathrm{Fe}^{2+}$ transport in non-grass-species that primarily rely on the reduction-based strategy for Fe uptake (Korshunova et al. 1999; Vert et al. 2001, 2002; Cohen et al. 2004; Schikora et al. 2006; Barberona et al. 2014). In contrast, grasses, including major cereal crops, rice, maize and wheat, mainly use the chelationbased strategy and rely on members of the YSL transporter family mediating transport of Fephytosiderophore chelates (Inoue et al. 2009; Lee et al. 2009c; Araki et al. 2011; Kakei et al. 2012; Senoura et al. 2017; Zhang et al. 2018). In addition, rice, maize, and barley also possess functional IRT1 homologs (Ishimaru et al. 2006; Li et al. 2015; Long et al. 2017).

Concerning IRT1-like proteins in non-grass species, the $A$. thaliana genome possesses three IRTs: AtIRT1, AtIRT2, and AtIRT3 (Vert et al. 2001, 2002; Lin et al. 2009). AtIRT1 localizes to the plasma membrane and participates in the absorption of essential metals including Fe, Zn, Mn, cobalt (Co), and also toxic metals such as $\mathrm{Cd}$ and $\mathrm{Ni}$ from the soil to root epidermal cells (Korshunova et al. 1999; Rogers et al. 2000; Nishida et al. 2011; Barberona et al. 2014). AtIRT2 localizes to intracellular vesicles and plays a role mainly in Fe and $\mathrm{Zn}$ compartmentalization into internal storage vesicles to alleviate metal toxicity (Vert et al. 2001, 2009). AtIRT3, localized to the plasma membrane and facilitates the uptake of Fe and $\mathrm{Zn}$ but not of $\mathrm{Cd}$ and $\mathrm{Mn}$ (Lin et al. 2009). IRT1 homolog from pea (Pisum sativum), PsIRT1 mediates Fe and Zn uptake as evidenced by its ability to complement growth of Saccharomyces cerevisiae Fe and Zn uptake mutants (Cohen et al. 1998, 2004); PSIRT2 localizes to the mitochondria and controls Fe transport in the vasculature (Alagarasan 2016). In tomato, both LeIRT1 and LeIRT2 transport Fe, Zn, Mn, and $\mathrm{Cu}$ (Schikora et al. 2006).

Concerning IRT1 homologs in grasses, rice (Oryza sativa), possesses two IRT1-like proteins, OsIRT1 and OsIRT2 that contribute to the uptake of Fe, $\mathrm{Zn}$ and $\mathrm{Cd}$ (Bughio et al. 2002; Ishimaru et al. 2006) but not Mn, Co, and Cu (Nakanishi et al. 2006; Lee et al. 2009a, b). Maize IRT1 homolog, ZmIRT1, localizes to the plasma membrane and endoplasmic reticulum of silk and embryos, and is involved in Fe and $\mathrm{Zn}$ transport (Li et al. 2015). IRT1 from barley (Hordeum vulgare), HvIRT1, plays an essential role in Mn uptake, translocation and grain accumulation (Long et al. 2017). These results indicate that although IRTs have broad transport substrate specificities and transport both essential and non-essential metals, their transport specificities and cellular localization differ among different species. Here, we thought to characterize IRT1 homoeologous from wheat. We specifically focused on Dwarf Polish Wheat (DPW) because it can accumulate high concentrations of $\mathrm{Cd}, \mathrm{Zn}$, and $\mathrm{Fe}$ in its seedlings without showing toxicity symptoms (Wang et al. 2016). DPW (Triticum polonicum L., $2 n=4 x=28, \mathrm{AABB}$ ) was originally collected from Tulufan, Xinjiang province, China, by Prof. Chi Yen of the Sichuan Agricultural University, China. In the present study, two IRT1 homoeologous, TpIRT1A and TpIRT1B have been isolated from DPW and analyzed for the tissue specificity of their expression, the subcellular localization and metal transport 
capabilities by using functional complementation studies in yeast and over-expressing TpIRT1B in $A$. thaliana. We have also initiated functional analysis of TpIRT1 homologs from tetraploid (T. dicoccum) and diploid ancestral (T. turgidum) wheat species.

\section{Materials And Methods}

\section{Plant materials and growth conditions}

Dwarf Polish wheat (DPW, Triticum polonicum L., $2 n=4 x=28$, AABB) were grown either hydroponically in the greenhouse or in the Wenjiang experimental field of Triticeae Research Institute $\left(30.6822^{\circ} \mathrm{N}\right.$, $103.8566^{\circ} \mathrm{E}$ ), Sichuan Agricultural University, Sichuan, China as detailed below. For analyses of the expression pattern of TpIRT1 homoeologs in different tissues, seeds of DPW were sowed on October 29th, 2015 and October 30th, 2016. Field trials were performed in a randomized complete block design with three replications, and each plot included one row with 20 plants. Tissues were collected at the three growth stages including the jointing stage (root, basal stem, leaf sheath, leaf blade, and young leaf), flowering stage (root, stem, leaf, leaf I, flag leaf, sheath, node, rachis, rachilla, lemma, palea, awn, ovary, and anther), and filling stage (root, stem, leaf, leaf I, flag leaf, sheath, node, rachis, rachilla, lemma, palea, awn, and immature grain). All tissues were frozen in liquid nitrogen, then stored at $-80^{\circ} \mathrm{C}$ for RNA isolation.

To impose Fe, Zn, Mn or Co deficiency, or Cd toxicity, the uniform-size seeds were sterilized for 15 min in $5 \%(\mathrm{~m} / \mathrm{v})$ sodium hypochlorite $(\mathrm{NaClO})$, rinsed five times with double-distilled water $\left(\mathrm{ddH}_{2} \mathrm{O}\right)$ and germinated on two layers of filter paper in glass Petri dishes. After five days of growth, uniform-size seedlings were transplanted into lucifugal plastic containers with a full Hoagland nutrient solution that was changed once per week. The full Hoagland nutrient solution contained $5 \mu \mathrm{M} \mathrm{ZnSO}_{4}, 250 \mu \mathrm{M} \mathrm{FeCl}_{3}$, $350 \mu \mathrm{M} \mathrm{MnCl}_{2}, 8 \mu \mathrm{M} \mathrm{CoCl}_{2}$. After two weeks of growth, a subset of seedlings was transferred to the same medium or to the medium lacking either $\mathrm{ZnSO}_{4}$, or $\mathrm{FeCl}_{3}$, or $\mathrm{MnCl}_{2}$, or $\mathrm{CoCl}_{2}$, or containing $25 \mu \mathrm{M} \mathrm{CdSO}$. After additional one week of growth, roots of plants were collected, frozen in liquid nitrogen, and stored at $-80^{\circ} \mathrm{C}$ for RNA isolation. In these experiments, plants were grown in the growth chamber under a $16 \mathrm{~h}$ light/ $8 \mathrm{~h}$ dark photoperiod, an irradiance of $150 \mu \mathrm{mol} \mathrm{mEm}{ }^{-2} \mathrm{~s}^{-1}$, a constant temperature of $23^{\circ} \mathrm{C}$, and relative humidity of $75 \%$. Each sample contains tissues that were pooled from five plants and experiments were repeated three times. Transgenic Arabidopsis lines generated as described below were grown in the growth chamber under $120 \mathrm{mEm}^{-2} \mathrm{~s}^{-1}$ illumination intensity, a $16 \mathrm{~h}$ light/ $8 \mathrm{~h}$ dark period, a constant temperature of $22^{\circ} \mathrm{C}$, and $50 \%$ humidity.

\section{RNA extraction, cDNA synthesis, and quantitative Real-Time PCR}

Total RNA was extracted using the Total RNA Kit II (Omega Bio-tek, Georgia, USA). The cDNA was synthesized from $2 \mu \mathrm{g}$ of total RNA using the M-MLV First Strand cDNA Synthesis Kit (Omega Bio-tek, Georgia, USA). qRT-PCR was performed in 96-well plates with CFX-96 ${ }^{\text {TM }}$ system (Bio-Rad Laboratories, 
California, USA) according to the user manual. The Actin gene (Forward-CCGATTGCTTGTTATCTGTT and Reverse-GAGGATGAAGACGAGAGTTT) was used to normalize the relative expression level of TpIRT1 (Wang et al. 2015). The relative expression was calculated using the software of Bio-Rad CFX manager $v 3.1$ with the $2^{-\Delta \Delta}$ Ct method (Livak and Schmittgen 2001). Statistical analysis was performed using Student's t-test $(p<0.05)$ in the software of IBM SPSS Statistics v22 (International Business Machines Corporation, New York, USA).

\section{Gene cloning, bioinformatics, and phylogenetic analysis}

The full-length cDNAs of TPIRT1A and TPIRT1B were amplified from leaves. PCR primers were selected based on the reference sequence of the wheat genome (Wang et al. 2016) were designed using Beacon Designer v7.0 (PREMIER Biosoft International, California, USA) (Table S1). Ten tetraploid wheat and two diploid ancestral species were used to investigate IRT1 homoeologs with the same primers (Table S2). Deduced amino acid sequences, gene structures, chromosome localization and phylogenetic analysis were predicated according to Jiang et al. (2017). Putative transmembrane (TM) domains were identified using TMHMM Server v2.0 (http://www.cbs.dtu.dk/services/TMHMM/).

\section{Functional complementation assays in Saccharomyces cerevisiae}

The open reading frames (ORFs) of TpIRT1A and TpIRT1B were sub-cloned into the yeast expression vector pYES2 (Invitrogen, Carlsbad, USA) using primers with the Hindll and Xbal sites (Table S1). These constructs and the empty vector (EV) were transformed into different yeast mutants as well as the isogenic wild-type BY4743 (MATa; his3 $\Delta 1$; leu2 $\Delta 0$; met15 $\Delta 0$; lys2 $\Delta 0$; ura3 $\Delta 0$ ), Cd-sensitive mutant $\Delta y c f 1$ (MATa; his3 $\Delta$; leu2 $\Delta 0$; lys2 $\Delta 0$; met15 $\Delta 0$; ura3 $\Delta 0$; YDR135c.:kanMX4), Zn-sensitive mutant $\Delta$ zrc1 (MATa; his3 $\Delta$ 1; leu2 $\Delta 0$; lys2 $\Delta 0$; met15 $\Delta 0$; ura3 $\Delta 0 ; Y M R 243 c .: k a n M X 4)$, and Co-sensitive mutant $\Delta \operatorname{cot1}(Y K 40)$ (MATa; ura3-52 his3-200, $\Delta$ cot1) (Euroscarf Lab, Germany). Transformants were selected for uracil prototrophy on yeast nitrogen base drop-out medium lacking uracil (SD-Ura) (Sigma, Missouri, USA) and by colony PCR using primer pairs specific to each TpIRT1 homoeolog. Functional complementation assays were performed on a solid or liquid SD-Ura media as described by Peng et al. (2018a) with minor modification for the concentration of mineral elements $\mathrm{Cd}(0 \mu \mathrm{M}$ and $40 \mu \mathrm{M}), \mathrm{Zn}(0 \mu \mathrm{M}$ and $4 \mathrm{mM})$, and Co $(0 \mu \mathrm{M}$ and $250 \mu \mathrm{M})$. For the functional complementation assays in a liquid medium, the single yeast colony was selected and grown overnight in SD-Ura liquid medium. The overnight culture was then diluted to an $\mathrm{OD}_{600}=0.8$ and one $\mathrm{mL}$ of the diluted yeast culture was added to a $50 \mathrm{~mL}$ of the SD liquid media with $1 \mathrm{mM} \mathrm{ZnCl}_{2}, 20 \mu \mathrm{M} \mathrm{CdCl}_{2}$, or $100 \mu \mathrm{M} \mathrm{CoCl}_{2}$, respectively. OD 600 was measured every 12 hours using a microplate spectrophotometer (Thermo Fisher Scientific, Massachusetts, USA) with three replicates per each measurement. Each experiment was repeated three times.

\section{The subcellular localization of TpIRT1A and TpIRT1B in the leaf protoplast of A. thaliana}

The ORFs of TPIRT1A and TPIRT1B without stop codon were individually fused at the $\mathrm{C}$ terminus with the modified green fluorescent protein (EGFP) and placed under the control of the cauliflower mosaic virus 
35S promoter (CaMV35s) in the pSAT6-N1-EGFP-Gate vector (Jung et al. 2012). TpIRT1A-EGFP and TpIRT1B-EGFP constructs and the vector lacking cDNA inserts were transfected into $A$. thaliana protoplasts prepared as described by Jung et al. (2012). EGFP-mediated fluorescence and chlorophyll auto-fluorescence were visualized and collected using FITC (for EGFP) or rhodamine (for chlorophyll) filter sets of the Axio Imager M2 microscope equipped with the motorized Z-drive and the high-resolution 25 Axio Cam MR Camera (Zeiss, Oberkochen, Germany).

\section{The generation and characterization of transgenic A. thaliana ectopically expressing TpIRT1B}

The ORF of TPIRT1B with the stop codon was inserted between Hindll and Xbal sites of the pCAMBIA1305.1 vector (Jefferson et al. 1987). The recombined constructs and the vector lacking the cDNA insert were individually transformed into $A$. thaliana wild-type ( $c v$. Col-0) by floral infiltration (Bent et al. 1994). Transgenic plants were selected on $1 / 2 \mathrm{MS}$ medium for the resistance to $25 \mathrm{mg} / \mathrm{L}$ hygromycin. The presence of TPIRT1B was also verified by PCR and sequencing using primer pairs TpIRT1B-HindII-F and TpIRT1A/B-Xbal-R (Table S1). The T4 generation of homozygous lines was used for analyses. The expression level of TpIRT1 in transgenic lines was analyzed by qRT-PCR as described above.

To test the role of TPIRT1B in mineral element deficiency and Cd toxicity, transgenic plants and $A$. thaliana wild-type were grown hydroponically. To do so, seeds were sterilized and treated with $4^{\circ} \mathrm{C}$ for two days, then sowed onto $1 / 2 \mathrm{MS}$ media. After one week, the uniform-size seedlings were transplanted into the fresh hydroponic medium containing $1.25 \mathrm{mM} \mathrm{KNO}_{3}, 0.5 \mathrm{mM} \mathrm{MgSO}_{4}, 0.625 \mathrm{mM} \mathrm{KH}_{2} \mathrm{PO}_{4}, 0.5$ $\mathrm{mM} \mathrm{Ca}\left(\mathrm{NO}_{3}\right)_{2}, 2.5 \mu \mathrm{M} \mathrm{NaCl}, 10 \mu \mathrm{M} \mathrm{Fe}(\mathrm{III})$-HBED, $3.5 \mu \mathrm{M} \mathrm{MnCl}_{2}, 0.25 \mu \mathrm{M} \mathrm{ZnSO}_{4}, 0.125 \mu \mathrm{M} \mathrm{CuSO}_{4}, 17.5$ $\mu \mathrm{M} \mathrm{H}_{3} \mathrm{BO}_{3}, 0.05 \mu \mathrm{M} \mathrm{Na}_{2} \mathrm{MoO}_{4}$, and $0.025 \mu \mathrm{M} \mathrm{CoCl}_{2}$. After two weeks of growth, a subset of plants was transferred either to the same medium or a medium with the reduced concentration of $\mathrm{ZnSO}_{4}(50 \mathrm{nM})$ or $\mathrm{Fe}$ (III)-HBED $(2.5 \mu \mathrm{M})$, or $\mathrm{MnCl}_{2}(3.5 \mu \mathrm{M})$, or $\mathrm{CoCl}_{2}(2.5 \mathrm{nM})$. A subset of plants was also transferred to a hydroponic medium with $20 \mu \mathrm{M} \mathrm{CdCl}_{2}$. Root lengths were measured after five days of growth for a subset (eight plants/line) of plants. In addition, roots and leaves were collected after two weeks of growth, dried at $80^{\circ} \mathrm{C}$ for two days, and dry weight was analysed.

To investigate tolerance to excess metals, the sterilized seeds of control and TpIRT1B-overexpression lines were sowed on $1 / 2 \mathrm{MS}$ medium plates with normal or elevated concentrations of one of the following mineral elements: Fe(III)-HBED $(250 \mu \mathrm{M}), \mathrm{MnCl}_{2}(0.8 \mathrm{mM}), \mathrm{CoCl}_{2}(25 \mu \mathrm{M}), \mathrm{CdCl}_{2}(20 \mu \mathrm{M})$, or ZnCl $\mathrm{Zn}_{2}(15$ $\mu \mathrm{M})$. After one week of growth, plants were imaged and root lengths were measured from eight plants per line, per experiment $(n=3)$.

\section{Inductively Coupled Plasma Mass Spectrometry (ICP-MS)}

Different plant lines were grown hydroponically for four weeks as described above. Plants were collected and mineral elements were desorbed from the root surface as described by Zhai et al. (2014). Briefly, plant roots were washed for $10 \mathrm{~min}$ in a medium containing $10 \mu \mathrm{M}$ EDTA (ethylenediaminetetraacetic acid), then transferred for 5 min to a medium containing $0.3 \mu \mathrm{M}$ BPS (4,7-diphenyl-1,10- 
phenanthrolinedisulfonic acid) and $5.7 \mathrm{mM} \mathrm{Na}_{2} \mathrm{~S}_{2} \mathrm{O}_{3}$, followed by five sequential washes in $\mathrm{ddH}_{2} \mathrm{O}$. Roots were then dried in $80^{\circ} \mathrm{C}$, ground, digested in $80 \%$ nitric acid at $220-280^{\circ} \mathrm{C}$, and plant residue was dissolved in $25 \mathrm{~mL}$ of $\mathrm{ddH}_{2} \mathrm{O}$. Mineral concentrations were determined by Inductively Coupled Plasma Mass Spectrometry (ICP-MS, Thermo Fisher Scientific, Massachusetts, USA).

\section{Perl's staining with $\mathrm{DAB} / \mathrm{H}_{2} \mathrm{O}_{2}$ Intensification}

The Perl's staining with $\mathrm{DAB} / \mathrm{H}_{2} \mathrm{O}_{2}$ (3,3'-diaminobenzidine tetrahydrochloride/Hydrogen peroxide) was performed according to Brumbarova and Ivanov (2014). Briefly, the five-day-old seedlings grown on $1 / 2 \mathrm{MS}$ media were collected and washed with $\mathrm{dd}_{2} \mathrm{O}$. Samples were vacuum-infiltrated ( $500 \mathrm{mbar}, 30 \mathrm{~min}$ ) with the fixation solution containing (methanol: chloroform: glacial acetic acid in 6:3:1 ratio) and washed with $\mathrm{ddH}_{2} \mathrm{O}$ for 1 min three times. Fixed samples were incubated with the pre-warmed staining solution (4\% $\mathrm{K}_{4} \mathrm{Fe}(\mathrm{Cn})_{6}: 4 \% \mathrm{HCl}$ in $1: 1$ ratio) for $15 \mathrm{~min}$ under vacuum (500 mbar) and washed with $0.1 \mathrm{M}$ phosphate buffer $(\mathrm{pH} 7.4)$ three times. For the intensification reaction, samples were applied with intensification solution (0.1 M Phosphate buffer $(\mathrm{pH} 7.0)$ containing $0.025 \% \mathrm{DAB}, 0.005 \% \mathrm{H}_{2} \mathrm{O}_{2}$, and $0.005 \% \mathrm{CoCl}_{2}$ ) for $10 \mathrm{~min}$, then the reaction was terminated by rinsing with $\mathrm{ddH}_{2} \mathrm{O}$. Samples were stored in $\mathrm{dd}_{2} \mathrm{O}$ one week prior to analyses. Images were collected using the Axio Imager M2 microscope equipped with the motorized Z-drive (Zeiss, Oberkochen, Germany).

\section{Results}

\section{Cloning and characterization of TPIRT1A and TpIRT1B}

TpIRT1A and TpIRT1B CDNAs were cloned from $A$ and $B$ genomes of DPW, respectively. The full-length cDNA of TpIRT1A included a 127 bp 5'-UTR, 1110 bp ORF, and 383 bp 3'-UTR; the full-length cDNA of TpIRT1B included a 124 bp 5'-UTR, 1119 bp ORF, and 104 bp 3'-UTR (Table S3). Alignment of the sequenced TpIRT1A and TpIRT1B to the reference sequence of the hexaploid wheat genome (The International Wheat Genome Sequencing Consortium 2018; Elizabeth 2018) revealed that TpIRT1A and TpIRT1B are localized on the chromosome 4AL (TRIAE_CS42_4AL_TGACv1_290140_AA0982100) and 4BS (TRIAE_CS42_4BS_TGACv1_328611_AA1090980), respectively, and each gene included an intron and two exons. Analysis of the deduced 370 and 373 amino acid sequences of TpIRT1A and TpIRT1B polypeptides, respectively, revealed that TpIRT1A shares $95.44 \%$ amino acid identity to TpIRT1B and each polypeptide contained eight predicted transmembrane domains (Table S3).

\section{The expression pattern of TpIRT1A/B in DPW}

To analyse the tissue-specificity and dynamics of the expression pattern of TpIRTTA and TpIRT1B we used plants at different developmental stages. Due to the high sequence identity of TpIRT1A and TpIRT1B genes, we were not able to identify specific regions for distinguishing the expression pattern of $T p I R T 1 A$ from TpIRT1B. Thus, the results below show the expression pattern for both TpIRT1A and $T p I R T 1 B$, and indicated from here on as $T P I R T 1 A / B$. We found that $T p I R T 1 A / B$ was highly expressed in 
flag leaves, followed by roots and lemma at the flowering stage (Fig. 1A). The high expression of $T p I R T 1 A / B$ in flag leaves and roots was maintained throughout the grain filling stage (Fig. 1B). In this developmental stage, the expression of $T p I R T 1 A / B$ was also evident in reproductive tissues including lemma, palea, awn, rachilla, and grain (Fig. 1B). At the jointing stage, TpIRT1A/B was highly expressed in old leaves and was also evident in roots with the lowest expression in young leaves (Fig. 1C). The expression of TpIRT1A/B was up-regulated only in response to $\mathrm{Mn}$, but not to $\mathrm{Fe}, \mathrm{Zn}$ or Co deficiencies (Fig. 1D). In contrast, the expression of $T$ IRIRT1A/B was considerably up-regulated by $\mathrm{Fe}, \mathrm{Mn}, \mathrm{Co}$, and $\mathrm{Cd}$, but not $\mathrm{Zn}$ excess (Fig. 1E).

\section{Subcellular localization of TpIRT1A and TpIRT1B}

To establish the cellular localization of TpIRT1A and TpIRT1B, TpIRT1A-EGFP, TpIRT1B-EGFP and the empty $P S A T 6-N 1-E G F P-G a t e$ vector were transiently expressed in protoplasts isolated from $A$. thaliana mesophyll cells. The EGFP signal from the pSAT6-N1-EGFP-Gate vector was found in the entire cell (Fig. 2A-C). The fluorescence of TpIRT1A-EGFP and TpIRT1B-EGFP-transfected protoplasts were detected at the cell periphery suggesting that both proteins are associated with the plasma membrane (Fig. 2E-L). The TPIRT1A-EGFP and TPIRT1B-EGFP-mediated fluorescence was also found to be associated with internal vesicles. While the nature of these vesicles is unknown, we speculate that they might be related to the endocytic pathway and participate in the recycling of TpIRT1A-EGFP and TpIRT1B-EGFP.

TpIRT1A and TpIRT1B increase the sensitivity of S. cerevisiae mutants lacking Cd and Co-transporters to metals

We next tested the transport capabilities of TpIRTTA and TpIRT1B using different $S$. cerevisiae mutants including: 1) a Cd-hypersensitive the Dycf1 mutant lacking the vacuolar ATP-binding cassette transporter responsible for the sequestration of $\mathrm{Cd}$, chelated with a ubiquitous cellular tripeptide, glutathione (Cd$\mathrm{GS}_{2}$ ) (Li et al. 1996); 2) a Co-sensitive mutant (Dcot1), lacking a Co transporter COT1 (Conklin et al. 1992; Bloß et al. 2002; Lang et al. 2011); 3) and Zn-hypersensitive mutant ( $\Delta z r c 1)$ lacking a vacuolarmembrane-localized transporter, ZRC1 (Miyabe et al. 2001).

As would be expected for plasma membrane-localized Cd uptake transporters, the expression of both TpIRT1A and TpIRT1B increased the sensitivity of the $\Delta y c f 1$ mutant to $40 \mu \mathrm{M} \mathrm{Cd}$ in a solid medium compared to the $\triangle y c f 1$ mutant expressing the vector without CDNA inserts (EV) (Fig. 3A). The increased sensitivity of $\triangle y c f 1-T p I R T 1 A$ and $\triangle y c f 1-T p I R T 1 B$ strains to Cd compared to the EV-transformed mutant was also observed in a liquid medium (Fig. 3B-C). Under Co stress, the expression of both TpIRT1A and TpIRT1B also enhanced the sensitivity of the COT1 mutant to $250 \mu \mathrm{M}$ Co on plates and $100 \mu \mathrm{M}$ Co in liquid media compared to EV (Fig. 3D-F). However, the growth of $\triangle z r c 1-T p I R T 1 A$ and $\triangle z r c 1-T p I R T 1 B$ was similar to $\Delta z r c 1-E V$ cell lines on solid or in liquid medium with high Zn (Fig. 3G-I).

Transgenic A. thaliana expressing TpIRT1B accumulates more Fe, Mn, and Co 
To determine the metal transport properties of $T p I R T 1$ in plants, we over-expressed TpIRT1B in Arabidopsis and generated two independent TPIRT1B-overexpressing lines (TPIRT1B-OE-L1 and TpIRT1B$O E-L 2$ ). The expression level of TPIRT1B in TPIRT1B-overexpressing lines was much higher than that in control lines (Fig. S1). Although TpIRT1B-overexpressing lines and control lines were indistinguishable when were grown under control conditions, the over-expression of TPIRT1B significantly increased Fe and $\mathrm{Mn}$ concentrations in leaves and roots of plants (Fig. 4A-F). The concentration of Co was elevated only in leaves in both TpIRT1B-OE lines compared to wild-type, correspondingly the translocation factor was also improved (Fig. 4G-I). Furthermore, Perls-DAB staining showed that plants ectopically expressing TpIRT1B accumulated more Fe at the root tip, the zone of maturation, the root-to-shoot junction, leaf vasculature, as well as stomatal area including stomatal cavity and guard cells of the leaf (Fig. 5).

\section{A. thaliana transgenic lines expressing TpIRT1B are more tolerant to Fe and Mn deficiencies}

We then exposed different plant lines to mineral deficiencies and, as expected, root and leaf biomass of control lines was significantly lower when they were grown under Fe or Mn deficiency and leaf biomass was lower when plants were grown under Co deficiency compared to plants grown under control conditions. Concerning TpIRT1B expressing plants, while Mn deficiency decreased root biomass, Fe and Co deficiencies decreased shoot biomass, overall, plant growth was less affected compared to wild-type or empty vector expressing plants (Fig. 6). Specifically, the over-expression of TpIRT1B partly rescued the plant root growth (Fig. 6E) and even increased the root length (Fig. 6D) and the leaf biomass (Fig. 6F) of Mn-deficient plants compared to control lines. Although no significant differences were found in root length or biomass between the transgenic and control lines grown under Co deficiency (Fig. 6G-H), leaf biomass was higher in TPIRT1B-overexpressing lines than in the wild-type or vector expressing plants (Fig. 6I). The increased tolerance of TpIRT1B-overexpressing plants to Fe, Mn, and Co deficiencies may result from their increased ability to accumulate these minerals when they are in abundance (Fig. 4) and use them under mineral deficiency. Consistently, as evidenced by the decreased root length of TPIRT1Boverexpressing lines, these plant lines were more sensitive than controls to elevated concentrations of $\mathrm{Fe}$, $\mathrm{Mn}$, and Co (Fig. S2). Interestingly, over-expression of TpIRT1B had no influence on plant growth under both either low or excess $\mathrm{Zn}$ and did not change internal $\mathrm{Zn}$ concentration when compared to control lines (Fig. S3).

\section{A. thaliana transgenic lines expressing TpIRT1B are more sensitive to Cd toxicity}

We then examined the sensitivity of TpIRT1B-overexpressing lines to excess $\mathrm{Cd}$. To do that different plant lines were gown either hydroponically (Fig. 7A-G) or on solid $1 \frac{1}{2} \mathrm{MS}$ medium (Fig. $7 \mathrm{H}$ ). The over-expression of TPIRT1B caused more serious toxicity symptoms including lesion and chlorosis of leaves, inhibited root lengths and decreased biomass when compared to control lines (Fig. 7A-D, H). Consistently, TpIRT1Boverexpressing plants accumulated more Cd in roots and leaves (Fig. 7E-G).

\section{The identification of IRT1 homoeologs from different wheat subgenomes}


We then used an in silico analysis to identify IRT1 homoeologs in different wheat genomes. Twenty IRT1 homoeologs that were isolated from ten tetraploid wheat genomes included ten homoeologs from the genome A and ten homoeologs from the genome B (Table S3). In addition, two IRT1 homoeologs, TuIRT1 and $A s I R T 1$, were also identified from two diploid wheat species T. urartu and Aegilops speltoides, and classified as TuIRT1A and AsIRT1B because T. urartu and A. speltoides are considered as the A and B genome donors, respectively (Haider 2013). The ORF lengths of a total of 22 IRT1 homoeologs ranged from 1094 bp to 1121 bp (Fig. S4), which encoded 363 to 372 amino acids (Fig. S5). According to amino acid alignment, two amino acid substitutions were identified in 12 IRT1A members while the other ten proteins shared the same sequence; five polymorphisms were found in IRT1B members (Fig. S5). Most IRT1 proteins were predicted to possess eight TMs, except for TdilRT1B that was predicted to have nine TMs (Fig. S6).

In total, 32 IRT1 proteins were grouped into two clades with $100 \%$ bootstrap values. All IRT1s from wheat were clustered into the Poaceae subclade (red arrow) with $96 \%$ bootstrap values (Fig. 8). All IRT1 homoeologs from A genome were grouped with 99\% bootstrap values (Fig. 8). Interestingly, TaIRT1D from the D genome of hexaploidy wheat was clustered with TpIRT1B and TdiIRT1B with 98\% bootstrap values (Fig. 8).

\section{Functional characterization of wheat IRT1 homoeologs}

To reveal the function of different IRT1 homoeologs, we individually introduced them into $\mathrm{Zn}, \mathrm{Cd}$ and Co sensitive yeast strains, $\Delta z r c 1, \Delta y c f 1$, and $\Delta \cot 1$ respectively. We found that two homoeologs were distinct from others in their ability to complement yeast mutants. First, the expression of TdilRT1B increased the sensitivity of the $\Delta z r c 1$ mutant to $\mathrm{Zn}$ toxicity when compared with other wheat IRT1s and empty pYES2 vector (Fig. 9C). Second, while all IRT1s tested increased the sensitivity of $\Delta y c f 1$ to Cd, the expression of TtuIRT1B dramatically increased Cd tolerance of this mutant strain (Fig. 9D-F). Meanwhile, TtuIRT1Bexpression did not affect the growth of $\triangle \cot 1$ mutant under Co stress in comparison to other $Y K 40-I R T 1 \mathrm{~s}$ that increased the Co sensitivity of this mutant (Fig. 9G-I). The comparison of IRT1 sequences disclosed that TdiIRT1B has two SNPs (571 and 773 sites) distinguishing it from other IRT1 homoeologs that converted the Histidine (His/H) to Tyrosine (Tyr/Y) at the positions of $193(\mathrm{H} 193 \mathrm{Y})$ and $260(\mathrm{H} 260 \mathrm{Y})$ (Fig. 9J). In addition, two SNPs were found in TtuIRT1B at positions 253 and 657 that converted Arginine $^{89}$ to $\mathrm{His}^{89}(\mathrm{R} 89 \mathrm{H})$ and Isoleucine ${ }^{230}$ to $\mathrm{Tyr}^{230}$ (I230T), respectively (Fig. 9J). The nucleotide variations in TdilRT1B and TtuIRT1B may have altered the function of these genes, causing the functional differentiation of metal transport.

\section{Discussion}

\section{TpIRT1B transports Fe, Mn, Co, and Cd transport, but not Zn unlike its homologs from other species}

In this manuscript, we show that TpIRT1B mediates uptake of Fe, Mn, Co, and $\mathrm{Cd}$, but not $\mathrm{Zn}$. This conclusion was made based on the following findings: first, the expression of TpIRT1B increased the 
sensitivity of $\Delta \cot 1$ and $\Delta y c f 1$ mutant yeast cells to Co and Cd, respectively. This suggests that TpIRT1B promoted the accumulation of $\mathrm{Co}$ and $\mathrm{Cd}$ in cells and caused toxicity. In contrast, $\mathrm{Zn}$ sensitivity of the $\Delta z r c 1$ did not change (Fig. 3). Second, the over-expression of TpIRT1B enhanced Fe, Mn, and Co concentrations in roots and shoots in $A$. thaliana and improved the tolerance of plants to these mineral deficiencies (Fig. 4-6). These data imply that Fe, Mn, and Co accumulation in plant tissues during growth under control conditions have helped to sustain normal growth under mineral deficiencies (Fig. 6) and increased the sensitivity to excess Fe, Mn, and Co stresses (Fig. S2). Third, the over-expression of TpIRT1B enhanced Cd concentration in roots and shoots, increasing the sensitivity to Cd stress (Fig. 7). Fourth, the over-expression of TpIRT1B in A. thaliana did not change $\mathrm{Zn}$ concentration and the growth of transgenic plants (Fig. S3).

Previous studies indicated that all IRTs from plants studied to date including AtIRT1, AtIRT2, AtIRT3, OsIRT1, OsIRT2, ZmIRT1, HvIRT1, LeIRT1, and LeIRT2 transport Fe and Zn; AtIRT1, HvIRT1, LeIRT1, and LeIRT2 transport Mn; AtIRT1, OsIRT1, OsIRT2, and HvIRT1 transport Cd; additionally, AtIRT2. AtIRT3, OsIRT1, and OsIRT2 do not transport Mn, Cd, and/or Co (Korshunova et al. 1999; Rogers et al. 2000; Vert et al. 2001, 2002; Bughio et al. 2002; Ishimaru et al. 2006; Nakanishi et al. 2006; Schikora et al. 2006; Pedas et al. 2008; Vert et al. 2009; Lin et al. 2009; Lee et al. 2009a, b; Nishida et al. 2011; Barberona et al. 2014; Li et al. 2015; Ismael et al. 2018). Since TpIRT1B from Polish wheat transports Fe, Mn, Co, and Cd, but not Zn, its transport function differs from its homologs in other species.

The TpIRT1 is preferentially expressed in roots, leaves, lemma, and palea (Fig. 1A-C). Previous studies demonstrated that OsIRT1 is mainly expressed in roots and leaves; AtIRT1, ZmIRT1, and HvIRT1 are mainly expressed in roots but also found in anthers (Bughio et al. 2002; Vert et al. 2002; Ishimaru et al. 2006; Li et al. 2015; Long et al. 2017). In this study, the TpIRT1 expression in roots was up-regulated by Mn deficiency (Fig. 1D). Surprisingly, TpIRT1 transcript abundance did not change in response to Fe, Zn or Co deficiency; on the contrary, its expression was up-regulated by excess $\mathrm{Fe}, \mathrm{Mn}$, and $\mathrm{Co}$ (Fig. 1D-E). Our results differ from reports on IRT1s from other species. Specifically, AtIRT1, OsIRT1, AhIRT1, LeIRT1, and $Z m I R T 1$ are up-regulated by Fe and $\mathrm{Zn}$ deficiencies; OsIRT1, AtIRT1, and HVIRT1 are up-regulated by Mn deficiency; AtIRT1 and ZmIRT1 are up-regulated and down-regulated by Fe and Zn deficiency and sufficiency, respectively (Vert et al. 2002, 2003; Ishimaru et al. 2006; Schikora et al. 2006; Lee and An 2009a; Ding et al. 2010; Shanmugam et al. 2010; Nakanishi et al. 2010; Li et al. 2013; Long et al. 2017; Zheng et al. 2018). Similar to AtIRT1 and OsIRT1, TpIRT1 was up-regulated by Cd toxicity (Fig. 1E). We also found that TpIRT1s were potentially located at plasma membrane and internal vesicles (Fig. 2). This result is in agreement with data showing that AtIRT1 resides at the plasma membrane and AtIRT2 on a periphery of small vesicles (Vert et al. 2001, 2002); ZmIRT1, in addition to plasma membrane is also associated with endoplasmic reticulum (ER) (Li et al. 2013). Together, our results suggest that TpIRT1 is involved in $\mathrm{Fe}, \mathrm{Mn}, \mathrm{Co}$, and $\mathrm{Cd}$ uptake and internal distribution in the plant.

It is well-recognized that non-gramineous plants use IRT1 to take up Fe(II) from the soil into root epidermal cells (Eckhardt et al. 2001; Varotto et al. 2002; Vert et al. 2002; Schikora et al. 2006; Hodoshima et al. 2007; Ding et al. 2009; Tan et al. 2015; Shanmugam et al. 2011). The non-gramineous plants absorb 
Fe-phytosiderophores using transporters from the YSL family, but not IRT1 (Lee et al. 2009c; Inoue et al. 2009). Previous studies have shown that rice and maize use both strategies and rely on IRT1 and YSL transporters to absorb Fe from the soil (Ishimaru et al. 2006; Li et al. 2013, 2015, 2018). In this study, we show that TpIRT1B is expressed mainly in roots and transports Fe. These results imply that wheat, similar to rice and maize, uses both strategies for Fe absorption.

Among mineral elements studied here, Co, is beneficial but can be toxic if in excess, while Cd is highly toxic for plant growth and development (Battersby 1993; Palit et al. 1994; Arfin et al. 1995; Komeda et al. 1997; Bakkaus et al. 2005; Järup and Åkesson 2009; Ismael et al. 2018). Thus, uptake and internal transport of these minerals in the plant relies on transporters for essential metals (Thomine et al. 2000; Morel et al. 2009; Cheng et al. 2011; Takahashi et al. 2011, 2014; Wang et al. 2017, 2019). It is noteworthy that global crop wheat, when grown on Cd-polluted soils, is an entry point of $\mathrm{Cd}$ into a daily human diet (Greger and Löfstedt 2004). To date, several essential metal transporters from wheat including TaHMA2, TaVP1, TpNRAMP3, TpNRAMP5 and TpNRAMP6 have been discovered to transport Co and/or Cd (Peng et al. 2008a, b; Khoudi et al. 2012; Tan et al. 2013; Wang et al. 2019). Our results show that TpIRT1B also transports $\mathrm{Co}$ and $\mathrm{Cd}$ (Fig. 4, 6, 7). Thus, these transporters may contribute to $\mathrm{Cd}$ accumulation in wheat, which therefore are available genes for genetic manipulation to reduce the $\mathrm{Cd}$ accumulation in the food chain.

\section{Amino acid residues involved in $\mathrm{Zn}, \mathrm{Cd}$, and Co transport in IRT1 homoeologs}

It has been shown that point substitutions of several pivotal amino acid residues in mineral ion transporters can change their substrate specificity (Zhao and Eide 1996a, b; Rogers et al. 2000; Grossoehme et al. 2006). For example, the replacement of the key lysine (Lys) residue in the intracellular loop of ZRT1 from yeast and AtIRT1 alters their transport specificity and the ability to transport Cd and Co (Gitan et al. 2000; Dubeaux et al. 2018). In this study, two His substitutions (H193Y and H260Y) of TdilRT1B increased the sensitivity of $\triangle z r c 1-T d i l R T 1 B$ strain to $\mathrm{Zn}$ stress when compared to other wheat IRT1s and the empty pYES2 vector (Fig. 9A-C, J). This result suggested that this polymorphism increased TdilRT1B specificity to Zn. Meanwhile, the unique substitution H260Y in TdilRT1B potentially caused an additional TM (TM9) between TM5 and TM6 as predicated by TMHMM v2.0 (Fig. S6). TMs form a potential ion channel and allow metal ions to pass through the cell membrane (Kadir et al. 2018). In the P1B-type ATPase family, the difference in TMs number appears to confer their capability to transport metals (Argüello et al. 2007). Thus, it is tempting to speculate that an additional TM9 in TdilRT1B might be a central component of $\mathrm{Zn}$ transport.

In addition, the expression of TtuIRT1B with two polymorphic residues (R89H and I230T) dramatically increased the tolerance of $\Delta y c f 1$ strain to Cd; while, the expression of other IRT1s in $\Delta y c f 1$ increased the sensitivity to Cd (Fig. 9D-F, J). Meanwhile, TtuIRT1B-expression did not change the growth of the $\Delta$ cot 1 strain under Co stress when compared to other YK40-IRT1s that were sensitive to Co (Fig. 9G-I). These results implied that the two polymorphic residues might change the transport properties of TtulRT1B or its subcellular localization, or the ability to bind $\mathrm{Cd}$ or $\mathrm{Co}$. For example, $\mathrm{Cd}$ normally binds to various 
amino acid residues including His, Glu, Cys, Asp and Tyr (Friedman 2014). Thus, His ${ }^{89}$ may be a potential Cd-binding site for intercellular mobilization at the IRT1. Consequently, the $1 \mathrm{e}^{230}$ seemed to be the Cobinding site, and its substitution may result in failing to transport Co in yeast.

\section{Conclusion}

Our results highlight the importance of TpIRT1 in the uptake and translocation of $\mathrm{Fe}, \mathrm{Mn}, \mathrm{Co}$, and $\mathrm{Cd}$. TpIRT1 is preferentially expressed in roots and leaves, and is significantly induced by Fe, $\mathrm{Mn}, \mathrm{Cd}$ and Co excess, and Mn deficiency. TPIRT1A and TPIRT1B localize at the plasma membrane and small internal vesicles in Arabidopsis protoplasts. The expression of TpIRT1A and TpIRT1B increased yeast sensitivity to $\mathrm{Cd}$ and $\mathrm{Co}$. The overexpression of TpIRT1B in Arabidopsis has led to $\mathrm{Fe}, \mathrm{Mn}$, and $\mathrm{Co}$ accumulation in plant tissues and partially rescued the plant defects under these metals deficiencies when compared to control lines. Meanwhile, the over-expression of TpIRT1B enhanced Cd concentration in Arabidopsis, resulting in the increased sensitivity of plants to Cd toxicity. Most of the IRT1 homoeologs that exist in abundant natural variations of wheat species have shown a similar function in $\mathrm{Zn}, \mathrm{Co}$, and Cd transport in yeast. However, four SNPs were detected that, we speculate, might change the metal transport specificity. Our future studies will focus on the discovery of amino acid residues that contribute to metal selectivity of IRTs in wheat.

\section{Declarations}

\section{Acknowledgments}

The authors thank associated Prof. Yan Huang (Sichuan Agricultural University) for supporting the plasmid of pCambia1305. We appreciate the help of Qiaoyi Zhang (Cornell University, USA) and Dr. Qiang Yi (Guizhou University, China) for the manuscript writing. The work in the Yonghong Zhou lab was supported by the National Natural Science Foundation of China (Grant No.: 31671688, 31670387 and 31870309). The work in the Vatamaniuk lab is funded by the Agriculture and Food Research Initiative Awards \# 2018-67013-27418 and 2021-67013-33798 from the USDA National Institute of Food and Agriculture. The funding agencies did not exert influence on the design of the study and collection, analysis, and interpretation of data and in writing the manuscript. The authors have no conflicts of interest to declare.

\section{Author contributions}

Y.J. and Y. W. designed the experiments. Y. J. performed most of experiments and analysed the data. Other authors assisted in experiments and discussed the results. Y. J., Y. W. and O. V. wrote the manuscript. 


\section{Declaration}

The authors declare that they have no known competing financial interests or personal relationships that could have appeared to influence the work reported in this paper.

\section{References}

Alagarasan G (2016) Cloning and characterization of iron regulated transporter gene (IRT) -associated with grain Fe content from little millet (Panicum sumatrense). Master Thesis, IGAU, India. https://krishikosh.egranth.ac.in/handle/1/72442

Araki R, Murata J, Murata, Y (2011) A novel barley yellow stripe 1-like transporter (HvYSL2) localized to the root endodermis transports metal-phytosiderophore complexes. Plant Cell Physiol 52(11): 1931-1940. https://doi.org/10.1093/pcp/pcr126

Arfin SM, Kendall RL, Hall L, Weaver LH, Stewart AE, Matthews BW, Bradshaw RA (1995) Eukaryotic methionyl aminopeptidases: two classes of cobalt-dependent enzymes. PNAS 92(17): 7714-7718. https://doi.org/10.1073/pnas.92.17.7714

Argüello JM, Eren E, González-Guerrero M (2007) The Structure and Function of Heavy Metal Transport P1B-ATPases. Biometals 20(3-4): 233-248. https://doi.org/10.1007/s10534-006-9055-6

Bakkaus E, Gouget B, Gallien JP, Khodja H, Carrot F, Morel JL, Collins R (2005) Concentration and distribution of cobalt in higher plants: the use of Micro-PIXE spectroscopy. Nucl Instrum Methods Phys 231(1): 350-356. https://doi.org/10.1016/j.nimb.2005.01.082

Barberona M, Dubeaux G, Kolbc C, Isonoc E, Zelaznyb E, Vert G (2014) Polarization of iron-regulated transporter 1 (IRT1) to the plant-soil interface plays crucial role in metal homeostasis. PNAS 111(22): 8293-8298. https://doi.org/10.1073/pnas.1402262111

Battersby AR (1993) Biosynthesis of Vitamin B12. Acc Chem Res 26(1): 15-21.

Benavidies MP, Gallego SM, Tomaro ML (2005) Cadmium toxicity in plants. Brazilian J. Plant Physiol 17(1): 21-34. http://dx.doi.org/10.1590/S1677-04202005000100003

Bloß T, Clemen S, Nies DH (2001) Characterization of the ZAT1p zinc transporter from Arabidopsis thaliana in microbial model organisms and reconstituted proteoliposomes. Planta 214: 783-791. https://doi.org/10.1007/s00425-001-0677-1

Bughio N, Yamaguchi H, Nishizawa NK, Nakanishi H, Mori S (2002) Cloning an iron regulated metal transporter from rice. J Exp Bot 53: 1677-1682. https://doi.org/10.1093/jxb/erf004

Bughio YF, Liang HM, Yang SY, Boch A, Clemens S, Chen CC, Wu JF, Huang JL, Yeh KC (2009) Arabidopsis IRT3 is a zinc-regulated and plasma membrane localized zinc/iron transporter. New Phytol 182: 392-404. 
Cheng J, Poduska H, Morton RA, Finan TH (2011) An ABC-Type cobalt transport system is essential for growth of Sinorhizobium meliloti at trace metal concentrations. J Bacteriol 193(17): 4405-4416. https://doi.org/10.1128/JB.05045-11

Cohen CK, Fox TC, Garvin DF, Kochian LV (1998) The role of iron-deficiency stress responses in stimulating heavy-metal transport in plants. Plant Physiol 116: 1063-1072. https://doi.org/10.1104/pp.116.3.1063

Cohen CK, Garvin DF, Kochian L (2004) Kinetic properties of a micronutrient transporter from Pisum sativum indicate a primary function in Fe uptake from the soil. Planta 218(5): 784-792. https://doi.org/10.1007/s00425-003-1156-7

Conklin DS, McMaster JA, Culbertson MR, Kung C (1992) COT1, a gene involved in cobalt accumulation in Saccharomyces cerevisiae. Mol Cell Biol 12(9): 3678-3688. https://doi.org/10.1128/MCB.12.9.3678

Curie C, Panaviene Z, Loulergue C, Dellaporta SL, Briat JF, Walker EL (2001) Maize yellow stripe1 encodes a membrane protein directly involved in Fe (III) uptake. Nature 409: 346-349.

https://doi.org/10.1038/35053080

Ding H, Duan L, Li J, Yan H, Zhao M, Zhang F, Li W (2010) Cloning and functional analysis of the peanut iron transporter AhIRT1 during iron deficiency stress and intercropping with maize. J Plant Physiol 167: 996-1002. https://doi.org/10.1016/j.jplph.2009.12.019

Ding H, Duan L, Wu H, Yang R, Ling H, Li WX, Zhang F (2009) Regulation of AhFRO1, an Fe (III)-chelate reductase of peanut, during iron deficiency stress and intercropping with maize. Physiol. Plant 136: 27483. https://doi.org/10.1111/j.1399-3054.2009.01219.x

Eckhardt U, Marques AM, Buckhout TA (2001) Two iron-regulated cation transporters from tomato complement metal uptake-deficient yeast mutants. Plant Mol Biol 45: 437-448. https://doi.org/10.1023/A:1010620012803

Gayomba SR, Zhai Z, Jung H, Vatamaniuk OK (2015) Local and systemic signalling of iron status and its interactions with homeostasis of other essential elements. Front Plant Sci 6: 716.

https://doi.org/10.3389/fpls.2015.00716

Grotz N, Guerinot ML (2006) Molecular aspects of $\mathrm{Cu}, \mathrm{Fe}$ and $\mathrm{Zn}$ homeostasis in plants. BBA-Mol. Cell Res 1763(7): 595-608. https://doi.org/10.1016/j.bbamcr.2006.05.014

Guerinot ML (2000) The ZIP Family of metal transporters. BBA-Biomembranes 1465(1-2): 190-198. https://doi.org/10.1016/S0005-2736(00)00138-3 
Hodoshima H, Enomoto Y, Shoji K, Shimad H, Goto F, Yoshihara T (2007) Differential regulation of cadmium-inducible expression of iron-deficiency-responsive genes in tobacco and barley. Physiol Plant 129: 622-634. https://doi.org/10.1111/j.1399-3054.2006.00825.x

Inoue H, Kobayashi T, Nozoye T, Takahashi M, Kakei Y, Suzuki K, Nakazono M, Nakanishi H, Mori S, Nishizawa NK (2009) Rice OsYSL15 is an iron-regulated iron (III)-deoxymugineic acid transporter expressed in the roots and is essential for iron uptake in early growth of the seedlings. J Biol Chem 284(6): 3470-3479. https://doi.org/10.1074/jbc.M806042200

Ishimaru Y, Suzuki M, Tsukamoto T, Suzuki K, Nakazono M, Kobayashi T, Wada Y, Watanabe S, Matsuhashi S, Takahashi M, Nakanishi H, Mori S, Nishizawa NK (2006) Rice plants take up iron as an $\mathrm{Fe}^{3+}$-phytosiderophore and as $\mathrm{Fe}^{2+}$. Plant J 45: 335-346. https://doi.org/10.1111/j.1365313X.2005.02624.x

Ismael MA, Elyamine AH, Moussa MG, Cai M, Zhao X, Hu C (2018) Cadmium in plants: uptake, toxicity, and its interactions with selenium fertilizers. Metallomics 2019(11): 255-277.

https://doi.org/10.1039/c8mt00247a

Ivanov R, Brumbarova T, Bauer P (2012) Fitting into the harsh reality: regulation of iron-deficiency responses in dicotyledonous plants. Mol Plant 5(1): 27-42. https://doi.org/10.1093/mp/ssr065

Järup L, Åkesson A (2009) Current status of cadmium as an environmental health problem. Toxicol Appl Pharmacol 238: 201-208. https://doi.org/10.1016/j.taap.2009.04.020

Jefferson RA, Kavanagh TA, Bevan MW (1987) GUS fusions: B-glucuronidase as a sensitive and versatile gene fusion marker in higher plants. EMBO J 6(13): 3901-3907. https://doi.org/10.1002/j.14602075.1987.tb02730.x

Jiang Y, Wang Y, Huang Z, Kang H, Sha L, Fan X, Zhang H, Gao S, Zhou Y, Yu X (2017) Cloning and characterization of four TpSnRK2s from dwarf polish wheat. Biol. Plant. 61(4): 601-610. https://doi.org/10.1007/s10535-017-0719-6

Jung H, Gayomba SR, Rutzke MA, Craft E, Kochian LV, Vatamaniuk OK (2012) COPT6 is a plasma membrane transporter that functions in copper homeostasis in Arabidopsis and is a novel target of SQUAMOSA promoter-binding protein-like 7. J Biol Chem 287(40): 33252-33267. https://doi.org/10.1074/jbc.M112.397810

Kadir AL, Stacey M, Barrett-Jolley R (2018) Emerging roles of the membrane potential: action beyond the action potential. Front Physiol 9: 1661. https://doi.org/10.3389/fphys.2018.01661

Kakei Y, Ishimaru Y, Kobayashi T, Yamakawa T, Nakanishi H, Nishizawa NK (2012) OsYSL16 plays a role in the allocation of iron. Plant Mol Biol 79: 583-594. https://doi.org/10.1007/s11103-012-9930-1 
Kobayashi T, Nishizawa N (2012) Iron uptake, translocation, and regulation in higher plants. Annu. Rev. Plant Biol 63: 131-152. https://doi.org/10.1146/annurev-arplant-042811-105522

Komeda H, Kobayashi M, Shimizu S (1997) A novel transporter involved in cobalt uptake. PNAS 94 (1): 36-41. https://doi.org/10.1073/pnas.94.1.36

Korshunova YO, Eide D, Clark WG, Guerinot ML, Pakrasi HB (1999) The IRT1 protein from Arabidopsis thaliana is a metal transporter with a broad substrate range. Plant Mol Biol 40(1): 37-44. https://doi.org/10.1023/A:1026438615520

Kumar R, Mehrotra NK, Nautiyal BD, Kumar R, Singh PK (2009) Effect of copper on growth, yield and concentration of $\mathrm{Fe}, \mathrm{Mn}, \mathrm{Zn}$ and $\mathrm{Cu}$ in wheat plants (Triticum aestivum L.). J Environ Biol (India) 30(4): 485-488.

Lang M, Hao M, Fan Q, Wang W, Mo S, Zhao W, Zhou J (2011) Functional characterization of BjCET3 and BjCET4, two new cation-efflux transporters from Brassica juncea L. J Exp Bot 62(13): 4467-4480. https://doi.org/10.1093/jxb/err137

Lee S, An G (2009a) Over-expression of OsIRT1 leads to increased iron and zinc accumulations in rice. Plant Cell Environ 32(4): 408-416. https://doi.org/10.1111/j.1365-3040.2009.01935.x

Lee S, Chiecko JC, Kim SA, Walker EL, Lee Y, Guerinot ML, An G (2009b) Disruption of OsYSL15 leads to iron inefficiency in rice plants. Plant Physiol 150: 786-800. https://doi.org/10.1104/pp.109.135418

Lee S, Jeon US, Lee SJ, Kim YK, Persson DP, Husted S, Schjørring JK, Kakei Y, Masuda H, Nishizawa NK, An G (2009c) Iron fortification of rice seeds through activation of the nicotianamine synthase gene. PNAS 106(51): 22014-22019. https://doi.org/10.1073pnas.0910950106

Li S, Zhou X, Chen J, Chen R (2018) Is there a strategy I iron uptake mechanism in maize? Plant Signal Behav 13(4): e1161877. https://doi.org/10.1080/15592324.2016.1161877

Li S, Zhou X, Huang Y, Zhu L, Zhang S, Zhao Y, Guo J, Chen J, Chen R (2013) Identification and characterization of the zinc-regulated transporters, iron-regulated transporter-like protein (ZIP) gene family in maize. BMC Plant Biol 13: 114. https://doi.org/10.1186/1471-2229-13-114

Li S, Zhou X, Li H, Liu Y, Zhu L, Guo J, Liu X, Fan Y, Chen J, Chen R (2015) Overexpression of ZmIRT1 and ZmZIP3 enhances iron and zinc accumulation in transgenic Arabidopsis. Plos ONE 10(8): E0136647. https://doi.org/10.1371/journal.pone.0136647

Li ZS, Szczypka M, Lu YP, Thiele DJ, Rea PA (1996) The yeast cadmium factor protein (YCF1) is a vascular glutathione S-conjugate pump. J Biol Chem 271(11): 6509-6517.

https://doi.org/10.1074/jbc.271.11.6509 
Long LZ, Persson DP, Duan F, Jørgensen K, Yuan L, Schjoerring JK, Pedas PR (2017) The iron-regulated transporter 1 plays an essential role in uptake, translocation and grain-loading of manganese, but not iron, in barley. New Phytol 217: 1640-1653. https://doi.org/10.1111/nph.14930

Miyabe S, Izawa S, Inoue Y (2001) The ZRC1 is involved in zinc transport system between vacuole and cytosol in Saccharomyces cerevisiae. Biochem Biophys Res Commun 282(1): 79-83.

https://doi.org/10.1006/bbrc.2001.4522

Nakanishi H, Ogawa I, Ishimary Y, Mori S, Nishizawa NK (2006) Iron deficiency enhances cadmium uptake and translocation mediated by the Fe ${ }^{2+}$ transporters OsIRT1 and OsIRT2 in rice. Soil Sci Plant Nutr 52: 464-469. https://doi.org/10.1111/j.1747-0765.2006.00055.x

Nishida S, Tsuzuki C, Kato A, Aisu A, Yoshida J, Mizuno T (2011) AtIRT1, the primary iron uptake transporter in the root, mediates excess nickel accumulation in Arabidopsis thaliana. Plant Cell Physiol 52(8): 1433-1442. https://doi.org/10.1093/pcp/pcr089

Palit S, Sharma A, Talukder G (1994) Effects of cobalt on plants. Bot. Rev. 60: 149-181

Pedas P, Ytting CK, Fuglsang AT, Jahn TP, Schjoerring JK, Husted S (2008) Manganese efficiency in barley: identification and characterization of the metal ion transporter HvIRT1. Plant Physiol 148: 455466. https://doi.org/10.1104/pp.108.118851

Peng F, Wang C, Cheng Y, Zeng J, Kang H, Fan X, Sha L, Zhang H, Zhou Y, Wang Y (2018a) Cloning and characterization of TpNRAMP3, a metal transporter from polish wheat (Triticum polonicum L.). Front Plant Scien 9: 1354. https://doi.org/10.3389/fpls.2018.01354

Peng F, Wang C, Zhu J, Zeng J, Kang H, Fan X, Sha L, Zhang H, Zhou Y, Wang Y (2018b) Expression of TpNRAMP5, a metal transporter from polish wheat (Triticum polonicum $\mathrm{L}$.), enhances the accumulation of Cd, Co and Mn in transgenic Arabidopsis plants. Planta 247: 1395-1406. https://doi.org/10.1007/s00425-018-2872-3

Pottier M, Oomen R, Picco C, Giraudat J, Scholz-Starke J, Richaud P, Carpaneto A, Thomine S (2015) Identification of mutations allowing natural resistance associated macrophage proteins (NRAMP) to discriminate against cadmium. Plant J 83: 625-637. https://doi.org/10.1111/tpj.12914

Qu S, Wang S, Chen W, Xu C, Zhang Z (2007) Identification in transgenic lines of malus robusta by introducing LeIRT12 gene. Sci Agric Sin (China) 40(9): 2015-2020.

Rogers EE, Eide DJ, Guerinot ML (2000) Altered selectivity in an Arabidopsis metal transporter. PNAS 97(22): 12356-12360. https://doi.org/10.1073/pnas.210214197

Sasaki A, Yamaji N, Ma JF (2014) Overexpression of OsHMA3 enhances Cd tolerance and expression of Zn transporter genes in rice. J Exp Bot 65(20): 6013-6021. https://doi.org/10.1093/jxb/eru340 
Schikora A, Thimm O, Linke B, Buckhout TJ, Müller M, Schmidt W (2006) Expression, localization, and regulation of the iron transporter LeIRT1 in tomato roots. Plant Soil 284(1): 101-108. https://doi.org/10.1007/s11104-006-0046-8

Senoura T, Sakashita E, Kobayashi T, Takahashi M, Aung MS, Masuda H, Nakanishi H, Nishizawa NK (2017) The iron-chelate transporter OsYSL9 plays a role in iron distribution in developing rice grains. Plant Mol Biol 95: 4-5. https://doi.org/10.1007/s11103-017-0656-y

Shanmugam V, Lo J, Wu C, Wang C, Lai C, Connolly EL, Huang J, Yeh K (2011) Differential expression and regulation of iron-regulated metal transporters in Arabidopsis Halleri and Arabidopsis Thaliana-the role in zinc tolerance. New Phytol 190: 125-137. https://doi.org/10.1111/j.1469-8137.2010.03606.x

Socha AL, Guerinot ML (2014) Mn-euvering manganese: the role of transporter gene family members in manganese uptake and mobilization in plants. Front Plant Sci 5: 106.

https://doi.org/10.3389/fpls.2014.00106

Song WY, Yamaki T, Yamaji N, Ko D, Jung KH, Fujii-Kashino M, Ma JF (2014) A rice ABC transporter, OsABCC1, reduces arsenic accumulation in the grain. PNAS 111(44): 15699-15704.

https://doi.org/10.1073/pnas.1414968111

Tan S, Han R, Li P, Yang G, Li S, Zhang P, Wang W, Zhao W, Yin L (2014) Over-expression of the MxIRT1 gene increases iron and zinc content in rice seeds. Transgenic Res 24(1): 109-122.

https://doi.org/10.1007/s11248-014-9822-z

Thomine S, Wang R, Ward JM, Crawford NM, Schroeder JI (2000) Cadmium and iron transport by members of a plant metal transporter family in Arabidopsis with homology to NRAMP genes. PNAS 97: 4991-4996. https://doi.org/10.1073/pnas.97.9.4991

Uriu-Adams JY, Keen CL (2005) Copper, oxidative stress, and human health. Mol Aspects Med 26: 268298. https://doi.org/10.1016/j.mam.2005.07.015

Urzica El, Casero D, Yamasaki H, Hsieh SI, Adler LN, Karpowicz SJ, Blaby-Haas CE, Clarke SG, Loo JA, Pellegrini M, Merchant SS (2012) Systems and trans-system level analysis identifies conserved iron deficiency responses in the plant lineage. Plant Cell 24: 3921-3948.

https://doi.org/10.1105/tpc.112.102491

Valko M, Morris H, Cronin MT (2005) Metals, toxicity and oxidative stress. Curr Med Chem 12(10): 11611208. https://doi.org/10.2174/0929867053764635

Varotto C, Maiwald D, Pesaresi P, Jahns P, Salamini F, Leister D (2002) The metal ion transporter IRT1 is necessary for iron homeostasis and efficient photosynthesis in Arabidopsis thaliana. Plant J 31(5): 589599. https://doi.org/10.1046/j.1365-313X.2002.01381.x 
Vert GA, Briat J, Curie C (2003) Dual regulation of the Arabidopsis high-affinity root iron uptake system by local and long-distance signals. Plant Physiol 132 (2): 796-804. https://doi.org/10.1104/pp.102.016089

Vert G, Barberon M, Zelazny E, Seguela M, Briat JF, Curie C (2009) Arabidopsis IRT2 cooperates with the high-affinity iron uptake system to maintain iron homeostasis in root epidermal cells. Planta 229(6):

1171-1179. https://doi.org/10.1007/s00425-009-0904-8

Vert G, Briat JF, Curie C (2001) Arabidopsis IRT2 gene encodes a root-periphery iron transporter. Plant J 26(2): 181-189. https://doi.org/10.1046/j.1365-313x.2001.01018.x

Vert G, Grotz N, Dedaldechamp F, Gaymard F, Guerinot ML, Briat JF, Curie C (2002) IRT1, an Arabidopsis transporter essential for iron uptake from the soil and for plant growth. Plant Cell 14: 1223-1233. https://doi.org/10.1105/tpc.001388

Wang R, Wang C, Yao Q, Xiao X, Fan X, Sha L, Zeng J, Kang H, Zhang H, Zhou Y, Wang Y (2019) The polish wheat (Triticum polonicum L.) TpSnRK2.10 and TpSnRK2.11 meditate the accumulation and the distribution of $\mathrm{Cd}$ and Fe in transgenic Arabidopsis plants. BMC Genomics 20: 210. https://doi.org/10.1186/s12864-019-5589-1

Wang Y, Wang C, Wang X, Peng F, Wang R, Jiang Y, Zeng J, Fan X, Kang H, Sha L, Zhang H, Xiao X, Zhou Y (2016) De novo sequencing and characterization of the transcriptome of dwarf polish wheat (Triticum polonicum L.). Int J Genomics ID5781412. https://doi.org/10.1155/2016/5781412

Wang Y, Wang X, Gu M, Kang H, Zeng J, Fan X, Sha L, Zhang H, Yu K, Zhou Y (2015) Cloning and characterization of four SnRK2 genes from Triticum polonicum. Biol Plant 59: 211-219. https://doi.org/10.1007/s10535-015-0501-6

Wierzbicka M, Przedpełska E, Ruzik R, Ouerdane L, Pol/ec'-Pawlak K, Jarosz M, Szpunar J, Szakiel A (2007) Comparison of the toxicity and distribution of cadmium and lead in plant cells. Protoplasma 231: 99. https://doi.org/10.1007/s00709-006-0227-6

Williams LE, Pittman JK, Hall JL (2000) Emerging mechanisms for heavy metal transport in plants. BBAMol Cell Res 1465(1): 104-126. https://doi.org/10.1016/S0005-2736(00)00133-4

Yamaji N, Sasaki A, Xia JX, Yokosho K, Ma JF (2013) A node-based switch for preferential distribution of manganese in rice. Nat Commun 4: 2442. https://doi.org/10.1038/ncomms3442

Yang Y, Xiong J, Chen J, Fu G, Chen T, Tao L (2016) Excessive nitrate enhances cadmium (Cd) uptake by up-regulating the expression of OsIRT1 in rice (Oryza sativa). Environ Exp Bot 122: 141-149. https://doi.org/10.1016/j.envexpbot.2015.10.001

Yuan M, Li X, Xiao J, Wang S (2011) Molecular and functional analyses of COPT/Ctr-type copper transporter-like gene family in rice. BMC-Plant Biol 11(1): 69. https://doi.org/10.1186/1471-2229-11-69 
Zhai Z, Gayomba SR, Jung HI, Vimalakumari NK, Piñeros M, Craft E, Vatamaniuk OK (2014) OPT3 is a phloem-specific iron transporter that is essential for systemic iron signalling and redistribution of iron and cadmium in Arabidopsis. Plant Cell 26(5): 2249-2264. https://doi.org/10.1105/tpc.114.123737

Zhang C, Shinwari KI, Luo L, Zheng L (2018) OsYSL 13 is involved in iron distribution in rice. Int J Mol Sci 19: 35-37. https://doi.org/10.3390/ijms19113537

\section{Figures}

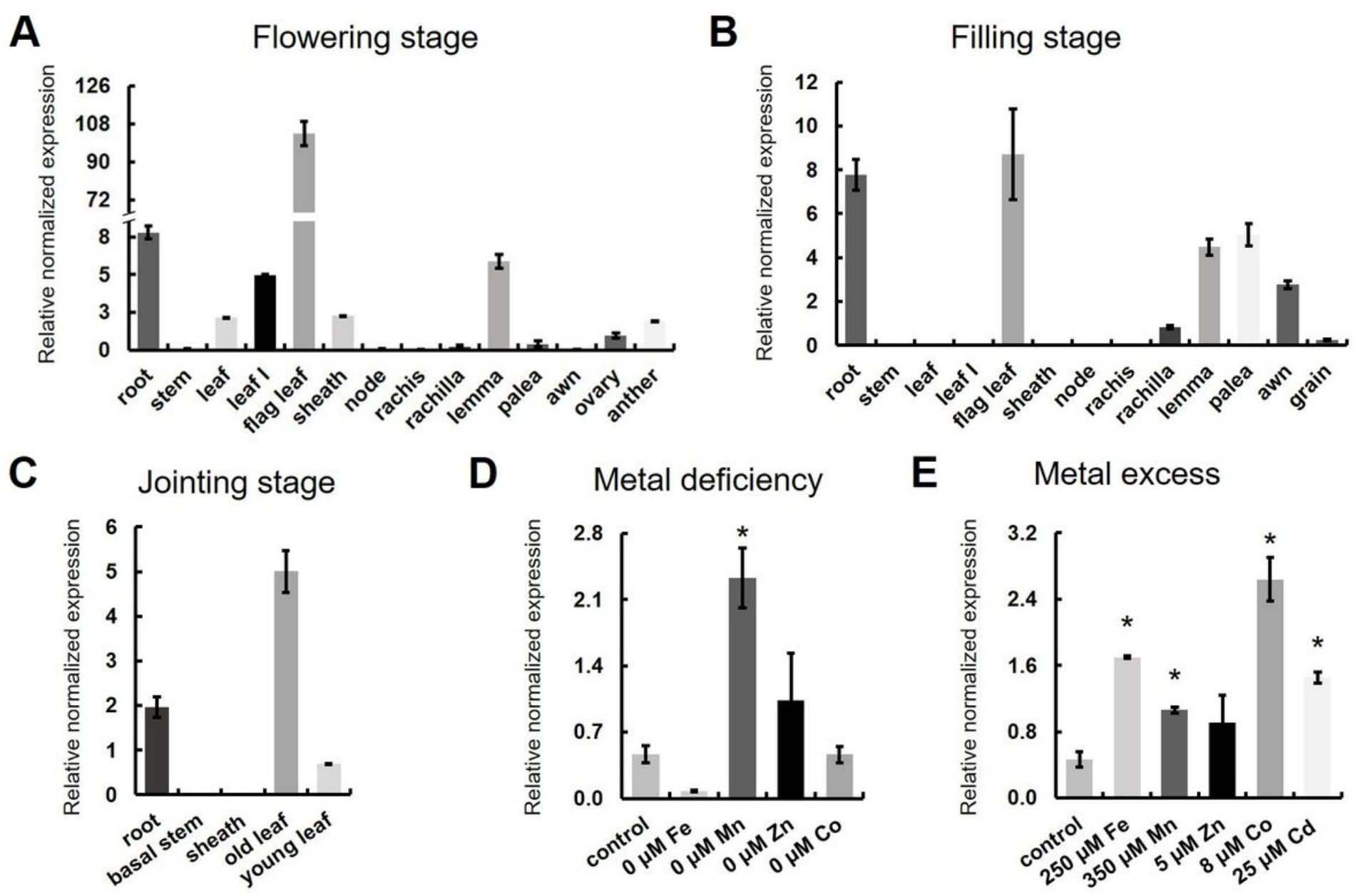

Figure 1

RT-qPCR analysis of the tissue expression pattern of TpIRT1A/B The expression patterns of TpIRT1A/B in different tissues of DPW were analysed at the flowering stage (A), the filling stage (B) and the jointing stage (C). The relative expression levels of TpIRT1 in roots was also analysed in plants subjected for one week to $\mathrm{Fe}, \mathrm{Mn}, \mathrm{Zn}$, Co deficiency (D) or metal excess (E). Asterisks indicate significant differences from control, grown under Fe, Mn, Zn, Co stresses ( $p<0.05$, Tukey's t-test, $n=3$ independent experiments). 

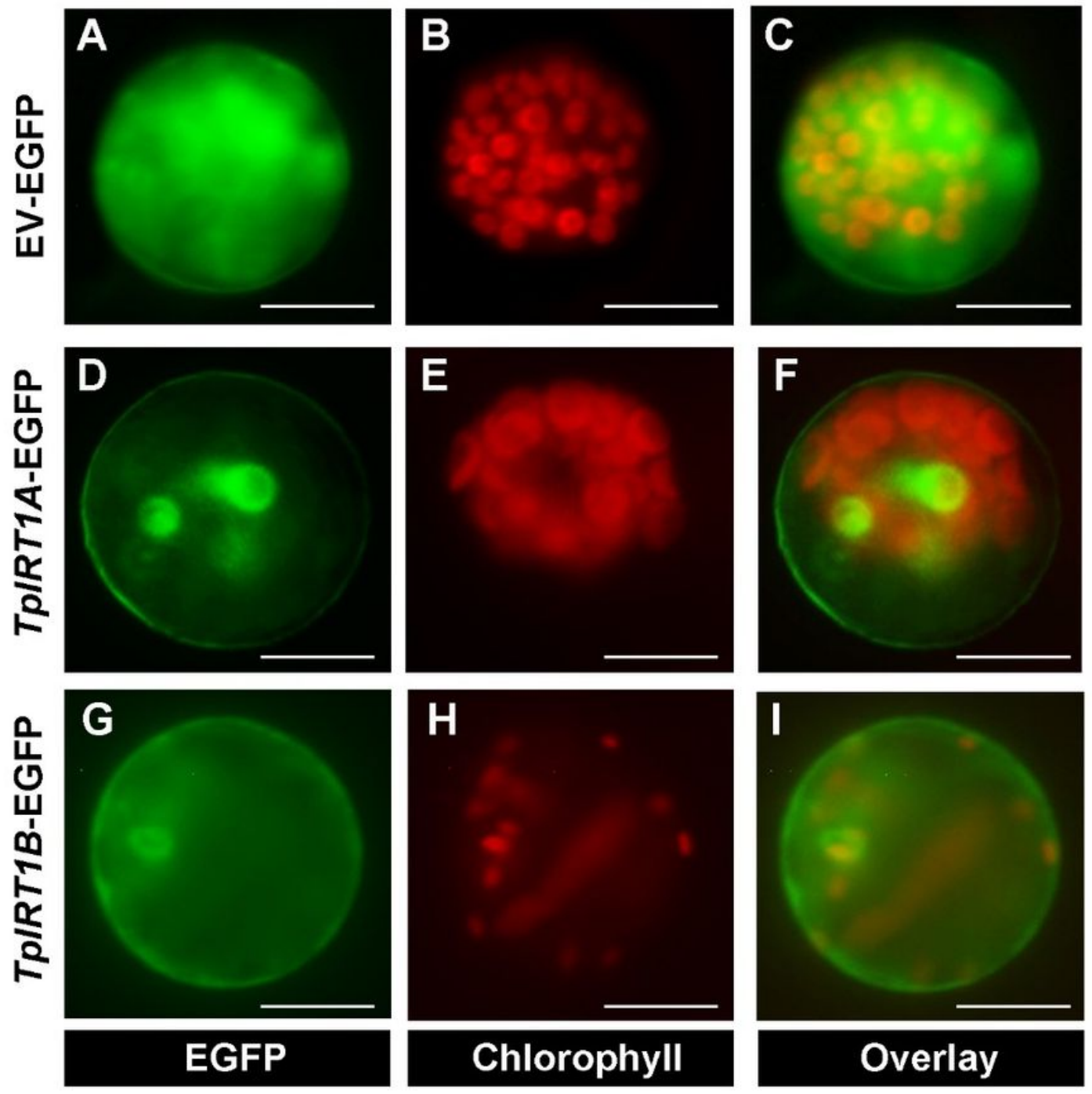

Chlorophyll

Overlay

Figure 2

The subcellular localization of TpIRT1A-EGFP and TpIRT1B-EGFP in A. thaliana protoplasts pSAT6-N1EGFP-Gate empty vector (EV, A-C), or the vector containing TpIRT1A (D-F) and TpIRT1B (G-I) cDNA inserts were transiently expressed in A. thaliana protoplasts. EGFP fluorescence (green), chlorophyll autofluorescence (red), and overlay(overlay) images are shown. Scale bar $=10 \mu \mathrm{M}$. 
A

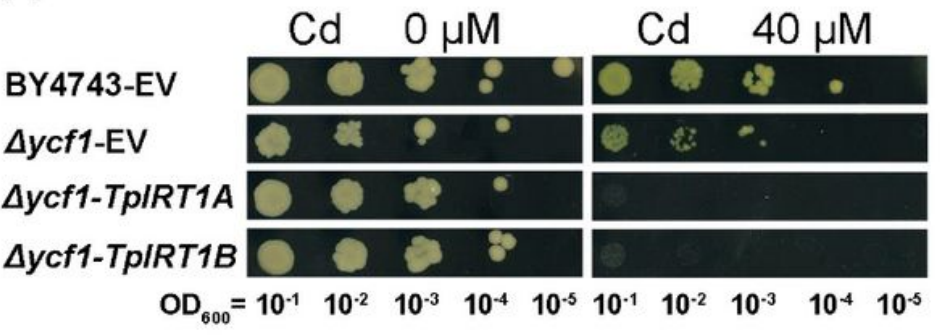

D

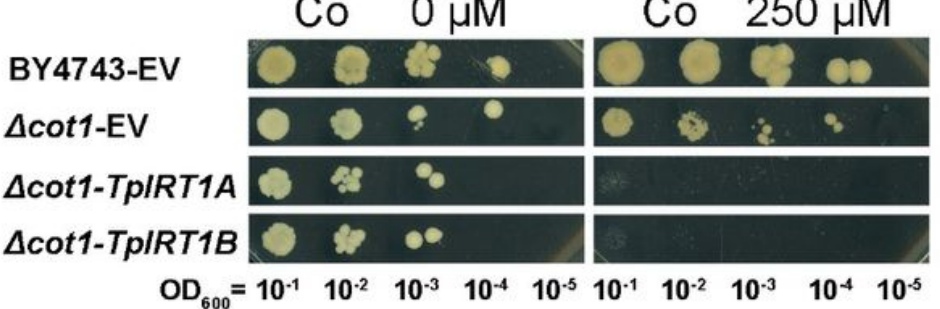

$\mathbf{G}$

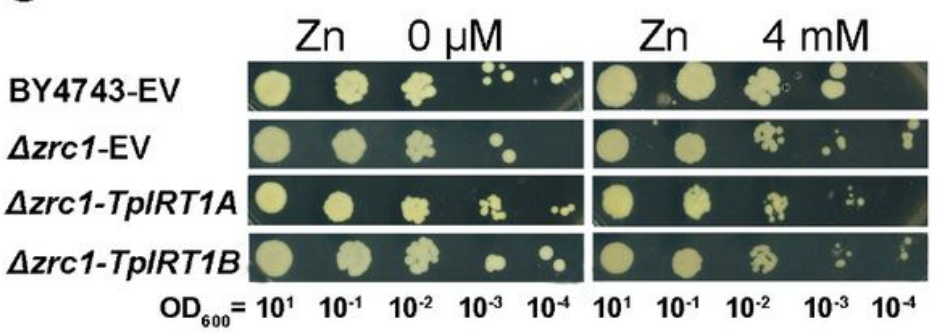

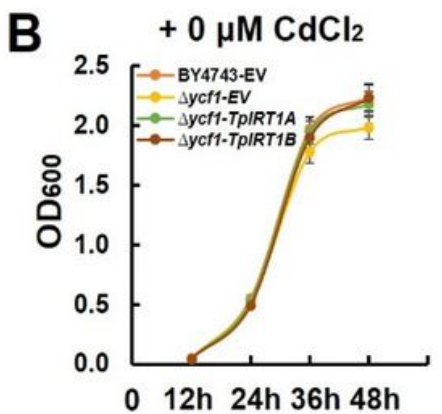

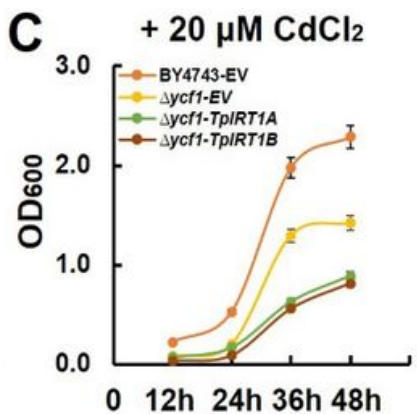

E
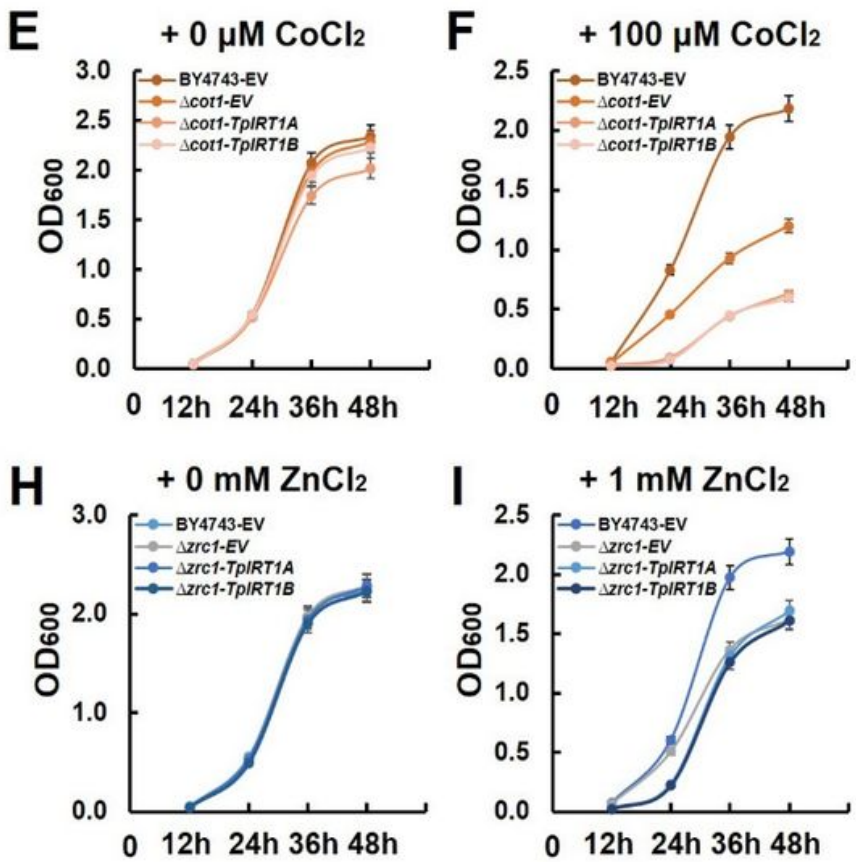

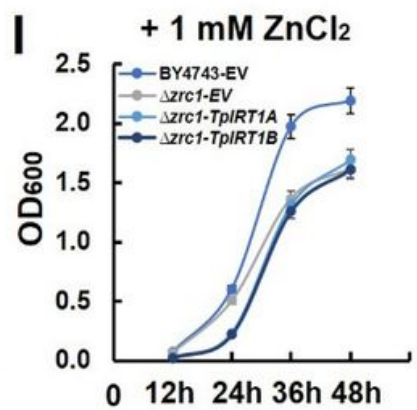

Figure 3

TpIRT1A and TpIRT1B increase $C d$ and Co sensitivity of yeast cells Cadmium sensitive $\Delta y c f 1$ yeast cells (A to $\mathrm{C}$ ), Co sensitive $\Delta \cot 1$ ( $D$ to $F$ ) or $Z n$ sensitive $\Delta z r c 1$ yeast cells (G) were transformed with the empty vector (EV) or a vector containing either TpIRT1A or TpIRT1B inserts. Cells were then spotted either on solid SD medium $(A, D, G)$ or inoculated into liquid SD media with the indicated concentration of metals $(B, C, E, F, H, I)$. A, D, and $G$ show representative images from three independent experiments. In $B, C, E, F$, $\mathrm{H}, \mathrm{I}$, the presented values are mean \pm standard deviation ( $\mathrm{n}=3$ independent experiments). 

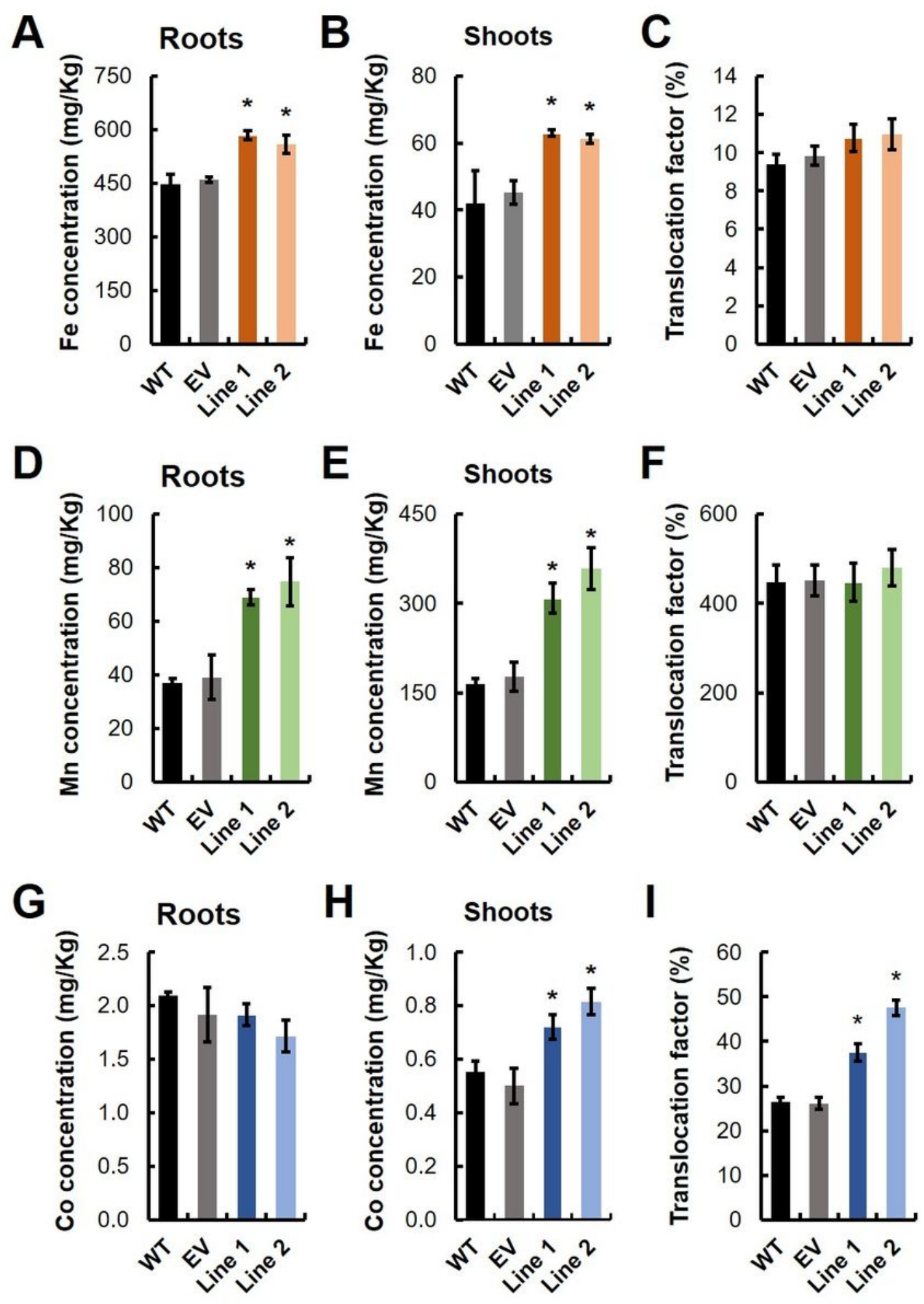

Figure 4

Tissues of A. thaliana ectopically expressing TpIRT1B accumulate more $\mathrm{Fe}, \mathrm{Mn}$, and Co The A. thaliana wild-type (WT), empty vector (EV) transformed plants and two TpIRT1B-overexpressing lines (Line 1 and Line 2) were grown hydroponically with the standard concentrations of minerals. Tissues of four-weekold plants were collected for ICP-MS analysis. (A to C) shows Fe concentration in roots (A), shoots (B) and Fe translocation from roots to shoots (C). (D to F) shows Mn concentration in roots (D), shoots (E) 
and $\mathrm{Mn}$ translocation from roots to shoots $(F)$. (G to I) shows Co concentration in roots $(G)$, shoots $(H)$ and Co translocation from roots to shoots (I). Asterisks indicate significant differences between WT and two TpIRT1B-overexpressing lines ( $p<0.05$, Student's t-test; $n=3$ independent experiments with tissues pooled from eight plants in each independent experiment).
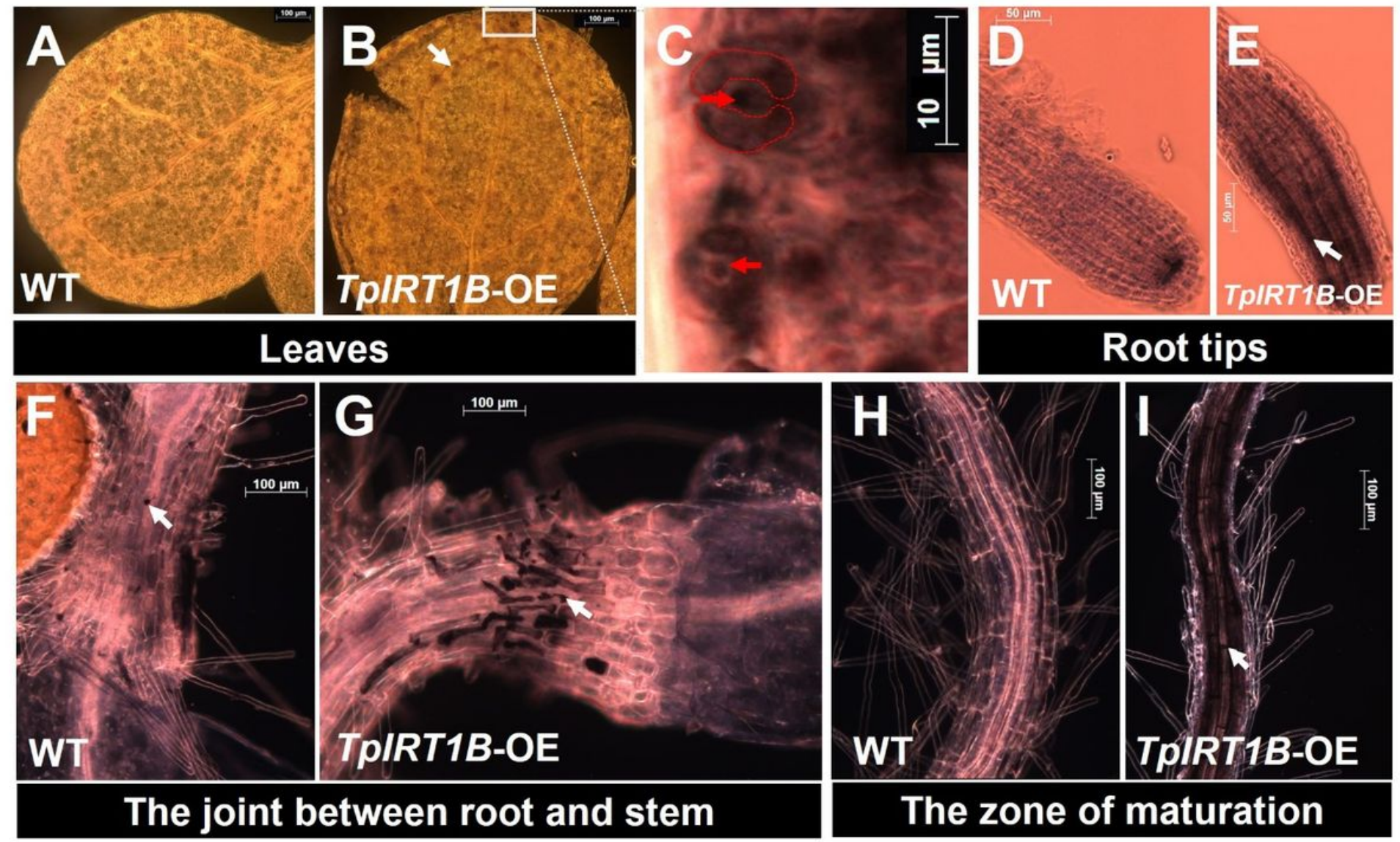

Figure 5

Perls-DAB staining to track Fe distribution in seedlings of WT and the TpIRT1B-overexpressing line The WT and the TpIRT1B-overexpressing line (TpIRT1B-OE) were grown on $1 \frac{1}{2}$ MS medium for 5 days prior to staining with Perls-DAB solution. Bright-field images of the entire leaf of WT (A), TpIRT1B-OE (B), and a close-up of TpIRT1B-OE leaf (C). (D to E) shows root tips of WT (D) and TpIRT1B-OE (E). ( $F$ to G) shows root-to-shoot junction in WT (F) and TpIRT1B-OE (G). ( $\mathrm{H}$ to I) shows the root zone of maturation WT $(\mathrm{H})$ and TpIRT1B-OE (I). White arrows indicate Fe-rich sites; red arrows mark Fe accumulation in stomatal areas in leaves; guard cells of stoma are marked by red lines in (C). Photos were taken using the Axio Imager M2 microscope. 


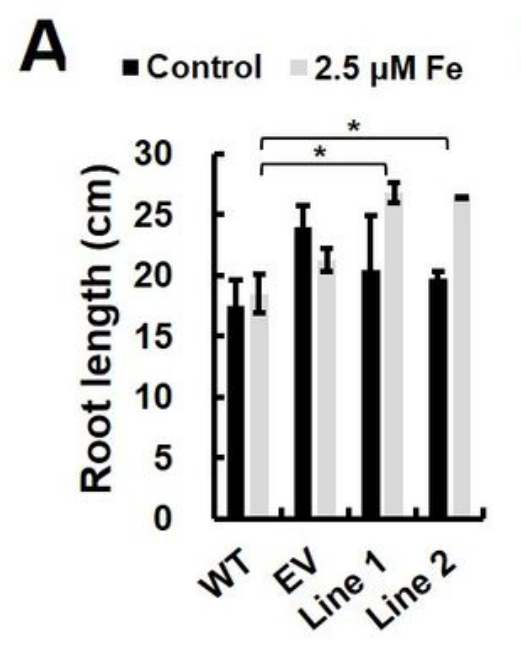

B - Control $2.5 \mu \mathrm{M} \mathrm{Fe}$

C. Control $2.5 \mu \mathrm{M} \mathrm{Fe}$

D.Control $3.5 \mu \mathrm{M} \mathrm{Mn}$
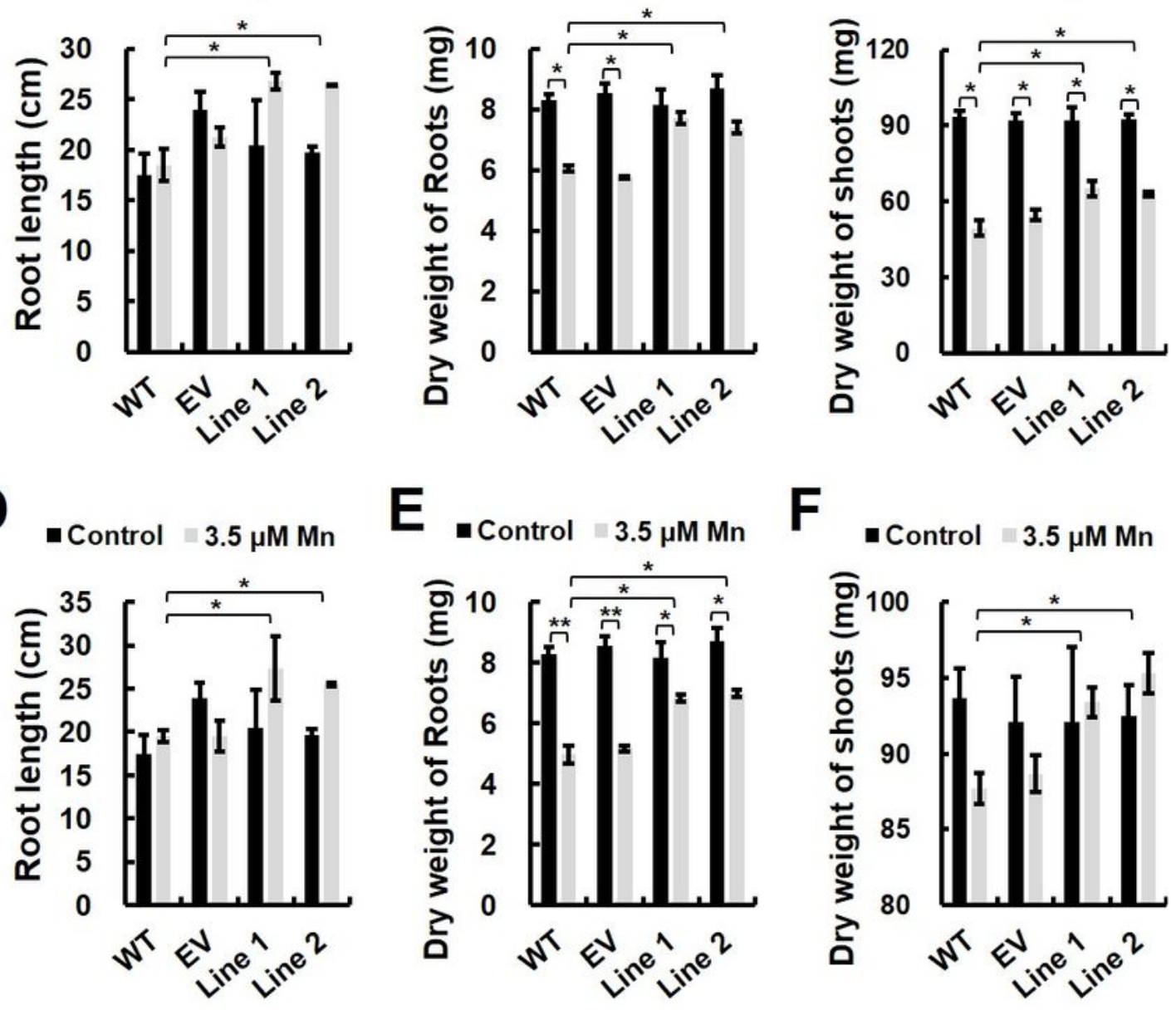

E - Control $=3.5 \mu \mathrm{M} \mathrm{Mn}$

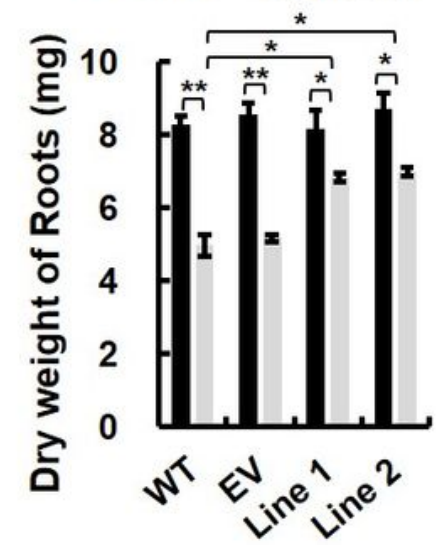

F
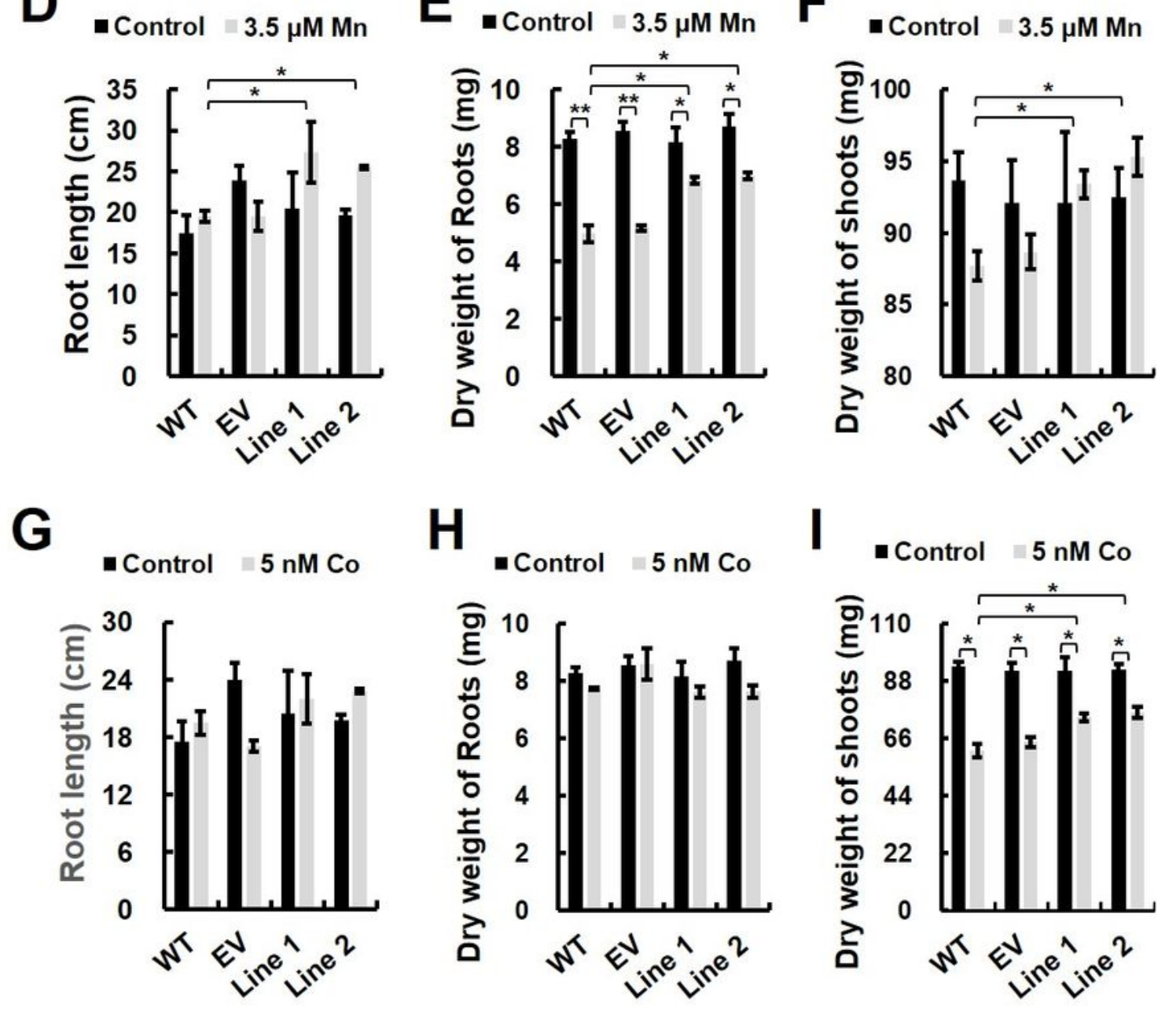

Figure 6

The phenotype and biomass of WT, EV- and TpIRT1B-overexpressing lines under low content of Fe, Mn, and Co stresses in hydroponics The WT, EV, and two TpIRT1B-overexpressing lines (Line 1 and Line 2) were grown hydroponically with the standard condition of minerals for two weeks, then treated with low content of $\mathrm{Fe}, \mathrm{Mn}$, and $\mathrm{Co}$ for one week, respectively. The root length, dry weight of roots and shoots were averaged with eight plants per genotypes from low content of Fe (A to C), Mn (D to F), and Co (G to I) 

vs. overexpressing lines by Student's t-test ( $p<0.05, n=3$ independent experiments).

A

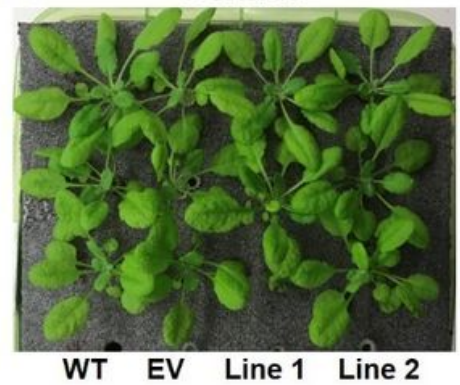

$20 \mu \mathrm{M} \mathrm{Cd}$

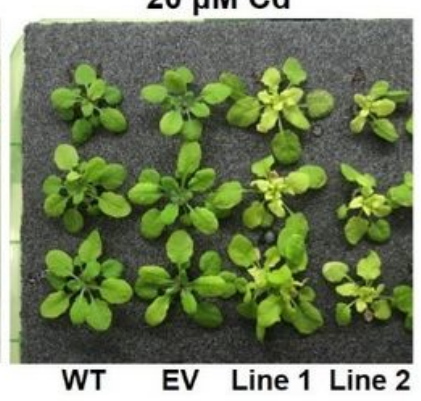

H

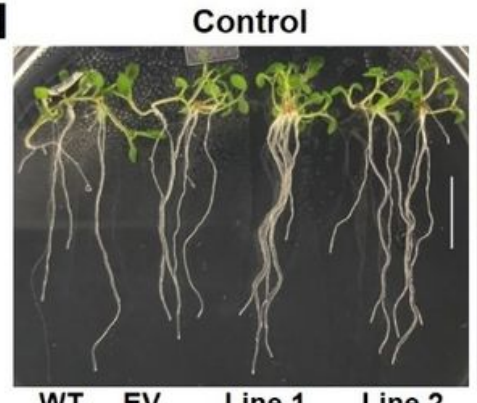

$20 \mu \mathrm{M} \mathrm{Cd}$

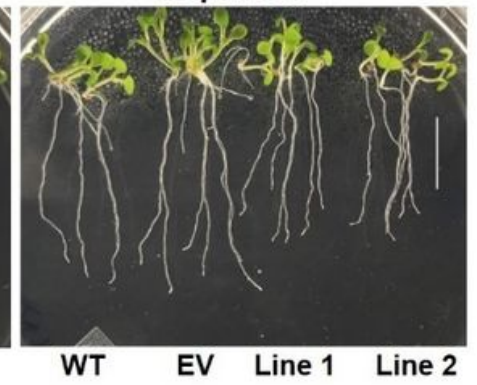

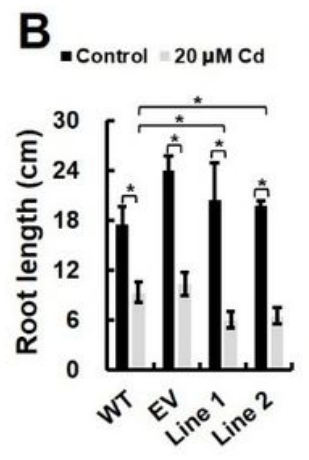
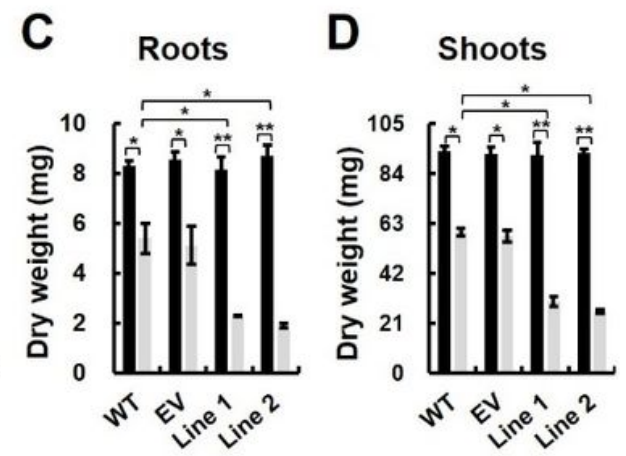

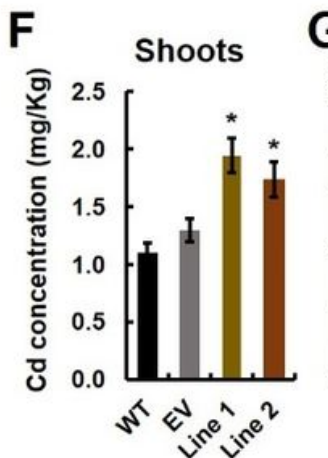

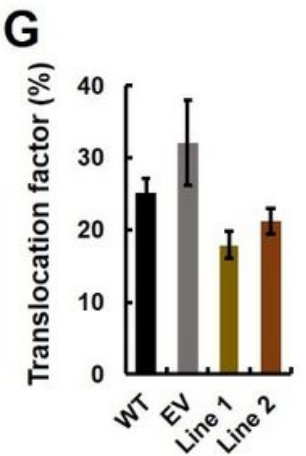

\section{Figure 7}

The TpIRT1B-overexpressing lines are more sensitive to $\mathrm{Cd}$ and accumulate more $\mathrm{Cd}$ than control lines under Cd stress The WT, EV, and two TpIRT1B-overexpressing lines (Line 1 and Line 2) were grown either hydroponically ( $A$ to $G$ ) or on solid $1 / 2 M S$ medium $(H)$. After two weeks of growth in hydroponics, plants were transferred to a fresh medium with or without $20 \mu \mathrm{M} \mathrm{CdCl} 2$. A subset of plants was imaged (A) and root lengths (B) were measured after five days of treatment. Another subset of plants was grown for two more weeks prior to tissue collection, the analysis of root and shoot biomass (C, D, respectively) and ICP$M S$ analysis ( $E$ to $G$ ). Asterisks indicate significant differences from control vs. Cd stress and WT vs. overexpressing lines $(p<0.05$, Student's t-test, $n=3$ independently experiments with tissues pooled from eight plants per genotype). $(\mathrm{H})$ shows a representative image of 7-day-old plants of indicated lines grown on $1 / 2 \mathrm{MS}$ soil medium with or without $20 \mu \mathrm{M} \mathrm{CdCl} 2$. 


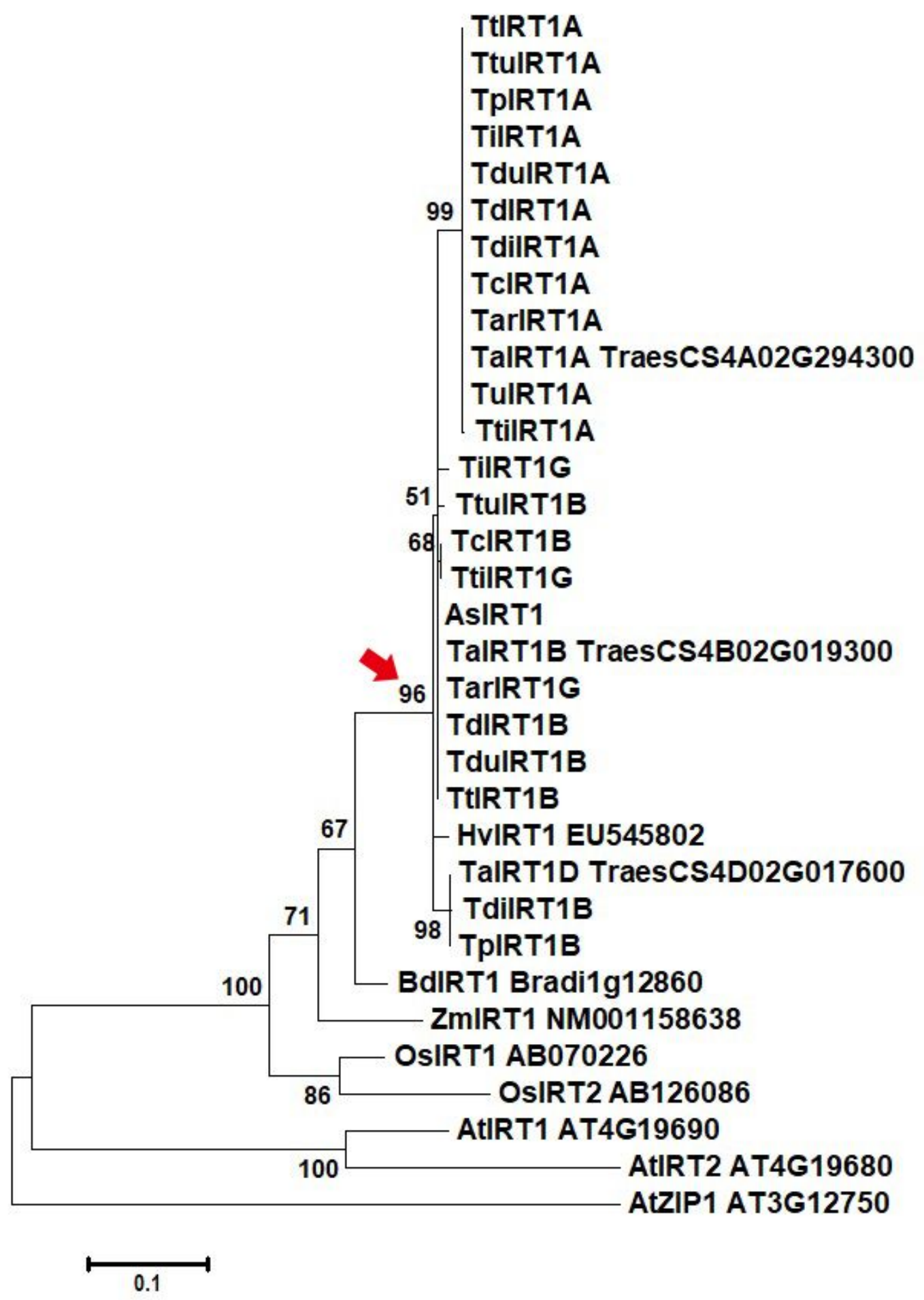

Figure 8

Phylogenetic tree of IRT1 proteins from Arabidopsis, rice, maize, Brachypodium, barley, and wheat genomes The neighbor-joining (NJ) tree of IRT1 proteins was performed by MEGA 6.0. AtZIP1 (AT3G12750) was used as an outgroup. Numbers at nodes indicate bootstrap values. Bar at the left bottom indicates the scale value. The red arrow indicates the Clade of Triticeae. 
A

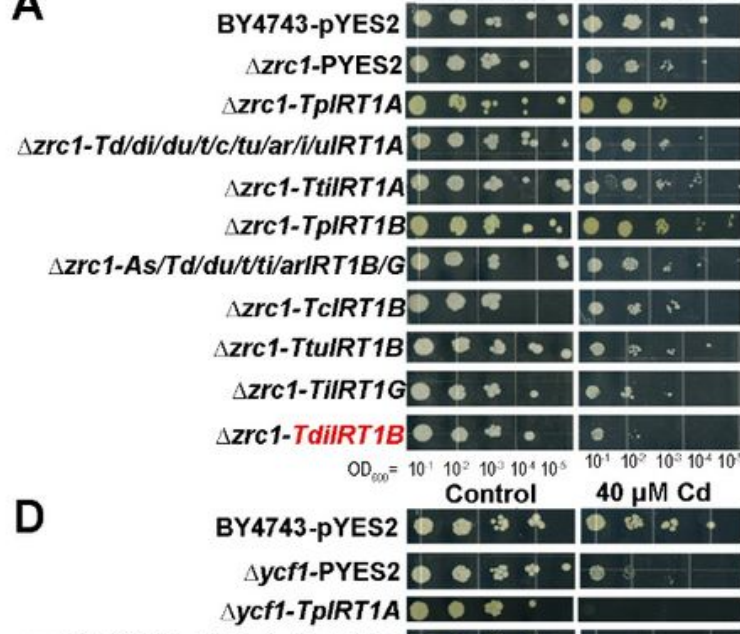

Aycf1-Td/di/du/t/c/tu/ar/i/ulRT1A O

Sycf1-TtIRT1A

$\triangle y c f 1-T P I R T 1 B O Q 0 \mathrm{~g}$

sycf1-As/Td/du/t/ti/arlRT1B/G @ •

Aycf1-TCIRT1B

$\triangle y c f 1-T$ tuIRT1B

Sycf1-TIIRT1GO \& के

Sycf1-TdilRT1B O * *

$O D=10^{1} 10^{2} 10^{3} 10^{4} 10^{-6} 10^{-1} 10^{2} 10^{3} 10^{4} 10^{3}$

G

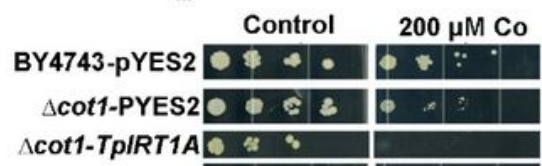

$\Delta c o t 1-T d / d i / d u / t / c / t u / a r / i / u I R T 1 A O \bullet$. *

$\triangle$ COt1-TtiRT1AO

$\triangle$ Cot1-TPIRT1BO

$\Delta \cot 1-A s / T d / d u / t / t i / a r I R T 1 B / G$

$\triangle$ Cot1-TCIRT1B 0

$\triangle$ cot1-TtuIRT1B 0 :

ACOT1-TIIRT1G O -

$\triangle$ Cot1-TdIRT1B

$O D_{m}=10^{\prime} 10^{2} 10^{3} 10^{-4} 10^{-5} 10^{-1} 10^{2} 10^{3} 10^{-4} 10^{5}$
B Control

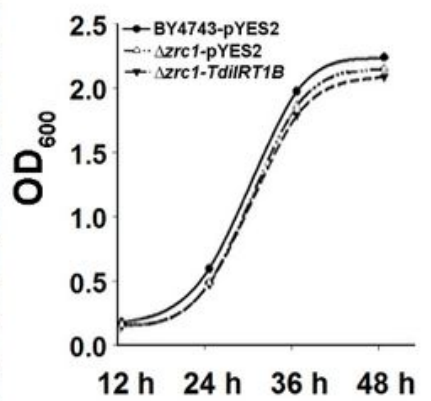

E

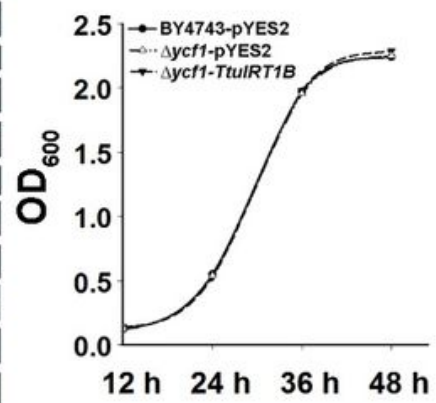

$\mathrm{H}$

Control

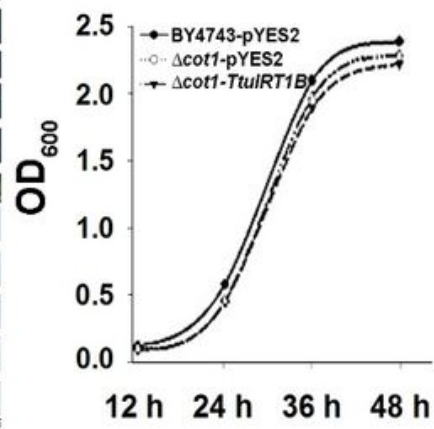

C $\quad 2 \mathrm{mMZn}$

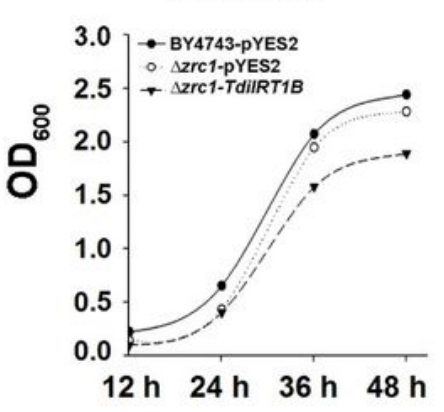

$\mathbf{F}$

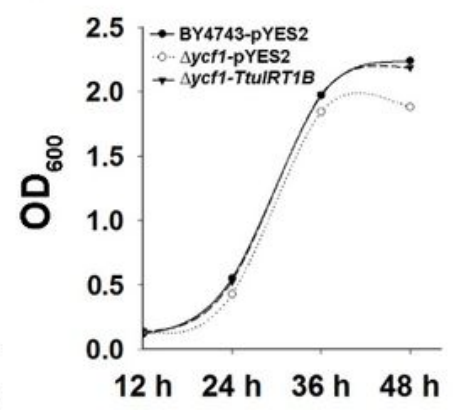

$100 \mu \mathrm{M}$ Co

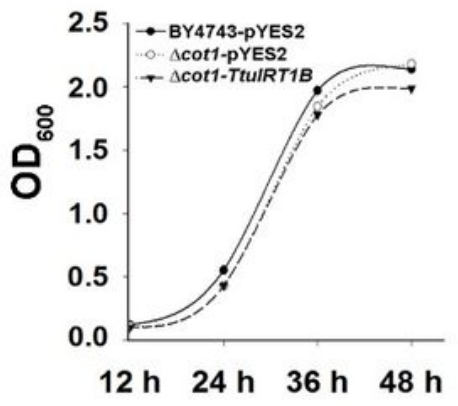

J

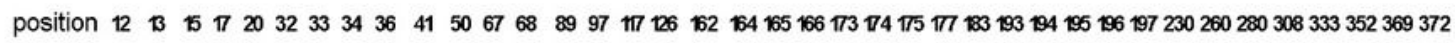
TPIRT1A S L L T T D P A A N V R A D E T..... S P H T H G H H K Q A A S Td/di/du/t/c/tu/ar/i/ulRT1A S L L L T T D P A A N V S R V D E T....". S L H TH G H H K Q A K A S TtilRT1A S L L L T D P A A N V S R A D T..... S L H T H G H H K Q A K S TpIRT1B S L L V S T D A S N V R A D DK. " A P S I H S G H H K A R A As/Td/du/t/ti/arIRT1B/G . L V S. . D S N V S R A N E K G A P. . S I H. . "I H K A A S A TCIRT1B. - L VST D P D N VSRA N E K G A . . S I H. . . I H K Q A S A TtuIRT1B. - LV S. . D S N V S H A N E K A P.. . S I H. . . TH K Q A R S A

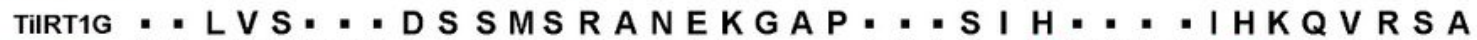
TdilRT1B S L L ST DPAS NVSRADDK. - A P A I YSHG H I Y KARSA

Figure 9

The substitution sites in TdilRT1B and TtulRT1B caused functional changes in yeast functional complementation assays IRT1 haplotypes or empty vectors were expressed in the indicated yeast mutants and spotted on solid SD medium supplemented with the indicated concentrations of $\mathrm{Zn}(\mathrm{A}), \mathrm{Cd}$ (B) and Co (D). Functional complementation assays were also performed in a liquid medium supplemented with $4 \mathrm{mM}$ Zn (D-E), $20 \mu \mathrm{M}$ Cd (F-G) or $100 \mu \mathrm{M}$ Co (H-I). Functional difference genes were 
marked in red. (J) shows all mutant sites and marked the pivotal sites that changed the sensitivities of yeast mutants in red.

\section{Supplementary Files}

This is a list of supplementary files associated with this preprint. Click to download.

- SuplementalTablesandFigures.docx 